\title{
Energy Potential of the Oceans in Europe and North America: Tidal, Wave, Currents, OTEC and Offshore Wind
}

This Chapter examines energy potential of the oceans in Europe and North America: tidal, wave, underwater currents, and ocean thermal energy conversion. It considers ocean wave and tidal power projects in San Francisco, wave power technologies (oscillating water column, overtopping devices, float systems, and hinged contour devices), and cost. Feasibility assessments of offshore wave and tidal current production are described, and wave project results are given. U.S wave energy resources, feasibility definition study sites, feasibility study for wave energy conversion (WEC) devices, demonstration scale plant design, commercial-scale plant design, learning curves, economics, and recommendations are discussed. Recent progress in offshore energy technology development including windpower is evaluated. Also discussed is the role of tidal power in the United Kingdom to reduce greenhouse gas emissions. Here, the proposed Severn Barrage is focused on considering potential benefits, conditions for sustainable development, energy policy context and compliance with environmental legislation. UK tidal resource is reviewed: stream resource (that is $\mathrm{KE}$ contained in fast-flowing tidal currents) and tidal range resources (that refers to gravitation potential energy). A feasibility study for tidal range in the Mersey Estuary and other schemes in the UK is summarized. Also given is a strategic overview of the Severn Estuary resource, electric output and characteristics, carbon emissions (carbon payback and carbon reduction) and physical implications of a barrage.

\subsection{Introduction}

Renewable energy sources from the oceans include offshore wind, wave energy, tidal energy, Ocean Thermal Energy Conversion (OTEC) and underwater currents. Harvesting ocean energy is not a new concept, yet it has remained a marginal resource. Today there is serious interest in offshore technology in Europe and Asia but funding for projects in power from the oceans at this time in USA is lacking. Wind farm technology has moved offshore where the prevailing winds can be more consistent and out of sight. Offshore wind energy is the fastest growing sector in renewable energy.

Areas of great tidal differences can produce regular and predictable tidal currents of 5 knots or more, creating large energy potentials. However, there are many areas with great tidal differences and only very slow currents. Tidal currents of 5 knots or more typically require a somewhat narrow passageway between a bay or estuary and the ocean and a somewhat shallow depth of the passageway. Tidal range, therefore, is not the only factor in speed of the tidal current. The Physics of Tidal Power is reviewed in Reference [1]. 
France has had a $240 \mathrm{MW}$ tidal power generating facility for 40 years. It is a tidal head plant and the technology is quite different [1].

Projects harnessing tidal currents have shifted toward capturing tidal-driven coastal currents. A study of 106 possible locations in the EU countries for tidal turbines showed that such sites could generate power of the order of 50 TWh per year. The power density of a marine current is approximately four times that for a wind generator, so this marine current resource is potentially large. However, there are fewer places in the world where marine currents are usable [1] compared with access to winds.

Wave energy can be considered as a concentrated form of solar energy. Winds are generated by the differential heating of the earth's surface, and, because they blow over large spans of water, part of their energy is converted into waves. The first commercial-scale wave power facility turning wave energy into compressed air was established in Scotland. Some proposed schemes involve hinged pontoons with hydraulics, while others appear like floating pistons that rise and fall with the wave action. Several prototype demonstrations are planned in the next few years. Growth in this sector is anticipated to reach at least $\$ 100$ million per annum by 2011.

The difference in temperature between the surface waters and the deeper ocean waters can produce significant thermal energy. Ocean-based renewable energy development lag landbased systems because of significant capital requirements and difficulty in obtaining the necessary financing due to risk and market barriers. The technical capabilities, both in engineering and management, exist in the offshore sector appear ready to undertake the size and scope of projects envisioned.

\subsection{Ocean Wave and Tidal Power Projects in San Francisco}

Ocean waves and Bay tides interacting with the Sacramento River flowing from the Sierra Nevada Mountains combine to create two excellent renewable energy resources, Long rolling ocean waves are a condensed form of wind energy. Tidal currents are driven primarily by the gravitational pull of the moon and are independent of local weather conditions [2].

San Francisco is undertaking two renewable energy projects: a pilot demonstration for tidal power that was commissioned in 2005 and a first U.S. commercial installation for wave energy that is proposed to produce up to $750 \mathrm{~kW}$. Both projects could be expanded in prudent phases to provide an important part of San Francisco's current 840MW peak demand. San Francisco is modeling these technologies for environmentally safe implementation in coastal and reverie communities round the world.

Wave power can be harvested by a variety of devices, with several unique approaches nearing commercialization. Most wave energy devices use air or seawater, and one devise produces electricity directly from motion, in addition to taking advantage of hydraulic pumps to generate power [3-9].

The Pelamis device for San Francisco [7] consists of a total of four cylindrical sections, which are connected together by three hydraulic power conversion modules. The total length of the device is $120 \mathrm{~m}$ and device diameter is $4.6 \mathrm{~m}$. The power conversion module comprises four 
hydraulic rams (two heave, two sway), high-pressure accumulators for power smoothing storage, two variable displacement motors for power conversion, and two $125 \mathrm{~kW}$ generators, with integrated transformer cabling AC power to shore. The device is secured by a compliant slack moored anchoring system. At a later date, a series of these devices can be installed to comprise a wave farm. By employing the Pelamis device, a generation capacity of $22 \mathrm{MW} / \mathrm{km}$ is anticipated. However, additional device optimization is anticipated.

The HydroVenturi tidal power generation device is comprised of a cube of venturi tubes attached to the marine bottom on a rack sited safely some $18 \mathrm{~m}$ below the surface and outside the navigation channel in the Golden Gate Passage. The tidal current flowing through the device is accelerated through the Venturi tubes to create a $2.5 \mathrm{Kg}$ pressure drop, thus creating suction enough to pull air down to an air storage tank integrated into the cube below the Venturi tubes. The compressed air is then pushed through a pipe to an on-shore air turbine to produce electricity. A $150 \mathrm{~kW}$ device has been demonstrated in England.

A 1MW Venturi commercial installation was expected for grid intertie by 2008, with expansion phased in $5-20 \mathrm{MW}$ increments. The air turbines in the commercial installation may be housed in a secure area on land under the Golden Gate Bridge. Several other tidal power generation locations have been identified in order to serve neighboring communities such as Marin County and Oakland.

San Francisco's interest in Hydro Venturi technology is because it has no moving parts underwater. A technology with no moving parts underwater makes tidal power attractive

\subsection{Wave Power Technologies}

Wave power technologies are now reviewed. The oceans contain a vast amount of mechanical energy in form of ocean waves and tides. The high density of oscillating water results in high energy densities, making it a favorable form of renewable energy. The total U.S. available incident wave energy flux is about 2,300 TWh/yr. The US Department of Energy (DOE) Energy Information Authority (EIA) estimated that 2003 hydroelectric generation in USA was about $270 \mathrm{TWh}$, which is a little more than a tenth of the offshore wave energy flux into the U.S. The fact that good wave and tidal energy resources can be found in close proximity to population centers and technologies being developed to harness the resource have a low visual profile makes this an attractive source of energy. Recent advances in offshore oil exploration technology and remote management of power generation systems have enabled significant progress in advancing technology development by simple technology transfer. However, despite enormous progress over recent years, underwater current and wave power conversion technologies are at an immature stage of development. This is because of a lack of accepted standards, a wide range of technical approaches, and large uncertainties on performance and cost of these systems. Further Research, Development and Demonstration (RD\&D) and the creation of early adopter markets through government subsidies is required to move these technologies into a competitive market place.

Feasibility assessments of wave and tidal current power are made in Section 4.4. 


\subsubsection{Wave Power Conversion Devices and Technologies}

Wave power conversion devices are installed either on-shore and embedded in a cliff or an existing harbor wall, near-shore in close proximity to shore standing on the seabed or offshore in deep waters. Similar to offshore wind, a wider applicability and more consistent and concentrated resource of energy can be found offshore and is more suitable for largescale deployments. Installing such devices away from the coastline solves many issues such as visual impact, permitting and environmental impact.

The device must be able to handle a wide range of incident wave power levels, from nearflat seas to the most extreme storm conditions (which produce waves power levels more than an order of magnitude above the average). Waves typically have a low frequency of the order of $0.1 \mathrm{~Hz}$, while power generation equipment runs at hundreds of rpm. The device must change the slow-acting, multi-directional wave force into a high-speed, unidirectional force capable of powering a generator. Short-term storage becomes an important consideration to maintain consistent power output.

Technologies to convert ocean wave power into electricity are many. The most promising ones are summarized below:

- Oscillating Water Column - (OWC) systems consist of a partially submerged structure, which forms an air chamber, with an underwater opening that allows the seawater to flow into the chamber. The volume of air inside the chamber is compressed as the water rises inside the chamber, driving air through a turbine. As the water level in the chamber subsides, the air is drawn back through the turbine. Both directional and self-rectifying air turbines have been developed. The axial-flow Wells turbine is the best-known turbine for this kind of application and has the advantage of not requiring rectifying air valves.

- Overtopping Devices - guides incoming waves up a ramp and up into a reservoir raised slightly above sea level. The water trapped in the reservoir flows back to the sea through a conventional low-head hydroelectric generator.

- Float Systems - Their common feature is a buoy that sits on the ocean's surface. The motion of this buoy is converted into electricity typically by a hydraulic power take off such as a hydraulic ram. These float systems come in different shapes and forms.

- Hinged Contour Devices - contains different floating sections, which are hinged together. As the wave passes, the sections move relative to each other and the hinges produce power. The power conversion uses hydraulic elements.

As part of a nationwide collaborative program to demonstrate offshore wave power technologies, the Electric Power Research Institute (EPRI) reviewed available technology options in 2004. Some of the results are outlined in Table 4.1. The wide range of different specifications is a clear indicator of the immaturity of this emerging market. Average power output was assessed for a typical Oregon wave climate with an incident wave power level of $21 \mathrm{~kW} / \mathrm{m}$. This is a typical US west coast wave power level.

The most important criteria assessing these devices are maturity of the development stage. This is indicated in Table 4.1 as Maturity Rating. 


\begin{tabular}{|l|l|l|l|l|l|}
\hline $\begin{array}{c}\text { Maturity } \\
\text { Rating }\end{array}$ & Company & $\begin{array}{c}\text { Device } \\
\text { Width (m) }\end{array}$ & $\begin{array}{c}\text { Device } \\
\text { Weight (Tons) }\end{array}$ & $\begin{array}{c}\text { Average } \\
\text { Power (kW) }\end{array}$ & Power Train \\
\hline 1 & $\begin{array}{l}\text { Ocean Power } \\
\text { Delivery }\end{array}$ & 4.6 & 380 & 153 & Hydraulic \\
\hline 2 & Energ-etech & 35 & 450 & 259 & Air Turbine \\
\hline 2 & Wave Dragon & 260 & 22,000 & 1369 & Low Head Hydro \\
\hline 2 & Wave Swing & 9.5 & NA & 351 & Linear Generator \\
\hline 3 & Wave Bob & 15 & 440 & 131 & Hydraulic \\
\hline 3 & Aqua Energy & 6 & 22 & 17 & Water Pump \\
\hline 3 & OreCON & 32 & 1250 & 532 & Air/Hydraulic \\
\hline 3 & INRI & 5.4 & 112 & 16 & Water Pump \\
\hline
\end{tabular}

Source: M. Previsic [10]

Table 4.1.Technology Comparison

\subsubsection{Electrical Interconnection}

Most wave power conversion devices under development incorporate frequency converters and step-up transformers to synchronize onto the grid. As a result, power quality tends to be good and power factors high. Short-term storage is incorporated to account for wave-towave variations. Storage options depend on the power take off train, and can incorporate hydraulic accumulators, storage through flywheel effects and capacitor banks. It remains to be seen how well these short-term storage options deal with the large variability of power levels in ocean waves.

Wave farm interconnection voltage levels depend on many variables, but are typically in the range of $12 \mathrm{kV}$ to $33 \mathrm{kV}$. Recent offshore wind projects in Europe showed that environmental risks prohibit use of oil insulated cables in the sensitive coastal environment. XLPE insulations have proven to be an excellent alternative, having no such potential hazards associated with devise operation.

\subsubsection{Cost}

An Ocean Power Delivery Pelamis wave energy conversion device was used to establish costing models for a commercial scale $(300,000 \mathrm{MWh} /$ year) wave farm. Levelized cost components are shown in Figure 4.1. Cost breakdown shows that impact on cost of electricity of Operation and Maintenance (O\&M) is significant and is the one component that has most uncertainty associated to it. The only way such O\&M costs can be driven down and confidence established is by building demonstration projects. 


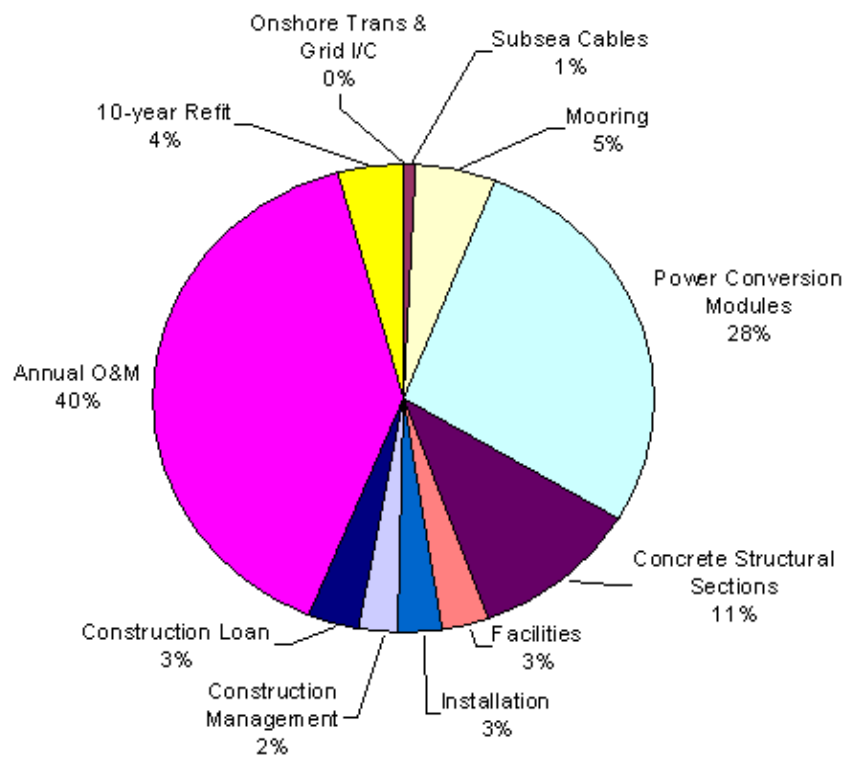

Source: M. Previsic [10]

Fig. 4.1. Breakdown of cost: Pelamis Wave Energy Conversion Device

An assessment of offshore wave energy conversion devices is made in References [10] and [11]. The methodology, guidelines and assumptions for conceptual design of offshore wave energy power plants is given in Reference [12]. System level design, preliminary performance and cost estimates for Hawaii, Oregon, Main, Massachusetts, and San Francisco Pelamis offshore wave power plants are given in References [13-17], respectively, and system level design, preliminary performance and cost estimate for the San Francisco Energetech offshore wave power plant is given in References [18]. Further, the state of the art for wave energy conversion is reviewed in Reference [19], and a technical assessment guide for ocean wave power is made in Reference [20]. A wave energy resource assessment for California is given in Reference [21].

Most of the EPRI Wave Power (WP) Reports [11, 13-18] are available on their website (www.epri.com).

\subsection{Feasibility Assessment of Offshore Wave and TIDAL CURRENT Power Production: A Collaborative Public/ Private Partnership}

Collaborative power production feasibility definition studies on offshore wave energy and tidal current energy on behalf of a number of public and private entities have been undertaken from 2004. The outcome of the offshore wave study under the Electric Power Research Institute (EPRI) is a compelling techno-economic case for investing in the research, development and demonstration (RD\&D) of technology to convert the kinetic energy of ocean waves into electricity.

EPRI Wave Power Reports [11, 13-18] and References [22-29] summarize the activities in this area. 


\subsubsection{Feasibility of Wave and Tidal Current Energy}

The elements of a wave and tidal current energy feasibility study are: a) Identify and characterize potential sites for assembling and deploying a power plant and for connecting the plant to the electric grid; b) Identify and assess wave energy conversion (WEC) devices; c) Conduct a conceptual design of a demonstration- and commercial-scale offshore wave power plant and, based on performance and cost estimates, assess the techno-economic viability of the wave energy source and the energy conversion technology; and d) Identify and assess the environmental and regulatory issues associated with implementing the technology.

Two characteristics of waves and tides important to the generation and dispatch of electricity from wave energy conversion devices are its variability and predictability. While the ocean is never totally calm, wave power is more continuous than the winds that generate it. The average power during the winter may be six times that obtained during the summer; however, power values may vary by a factor of a hundred with the random occurrences of storms. Therefore, the power of waves is highly variable. The predictability of wave energy is of the order of a few days. The waves resulting, for example, from storms that occur off the coast of Japan, will take that long to reach the northwest cost of the United States. The power from tidal currents, on the other hand, typically varies according to a diurnal cycle. The major benefit of tidal power is its high predictability for a given site years in advance, provided there is a thorough knowledge of the site. A drawback of tidal power is its low capacity factor, and that its peak availability misses peak demand times because of the 12.5-hour cycle of the tides.

Ocean waves are generated by the winds that result from uneven heating around the globe. Waves are formed by winds blowing over the water surface, which make the water particles adopt circular motions as depicted in Figure 4.2. this motion carries kinetic energy, the amount of which is determined by the speed and duration of the wind, the length of sea it blows over, the water depth, sea bed conditions and also interactions with the tides. Waves occur only in the volume of water closest to the water surface, whereas in tides, the entire water body moves, from the surface to the seabed.

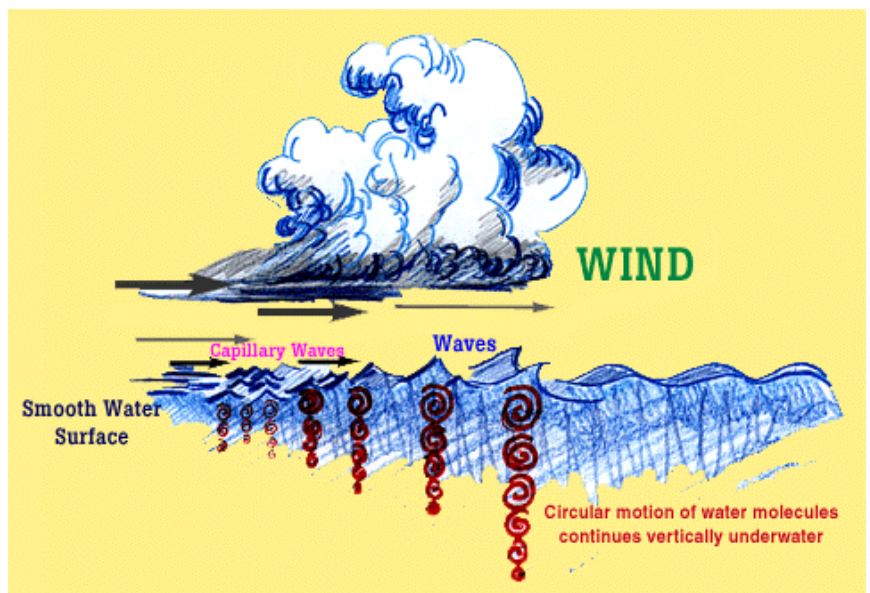

Source: M. Previsic [10]

Fig. 4.2. Wave generating forces based on wind-water interaction 
The tides are generated by rotation of the earth within the gravitational fields of the moon and sun [1]. The relative motion of these bodies causes the surface on the oceans to be raised and lowered periodically, as illustrated in Figure 4.3. The physics of tidal power is explained in Reference [1].

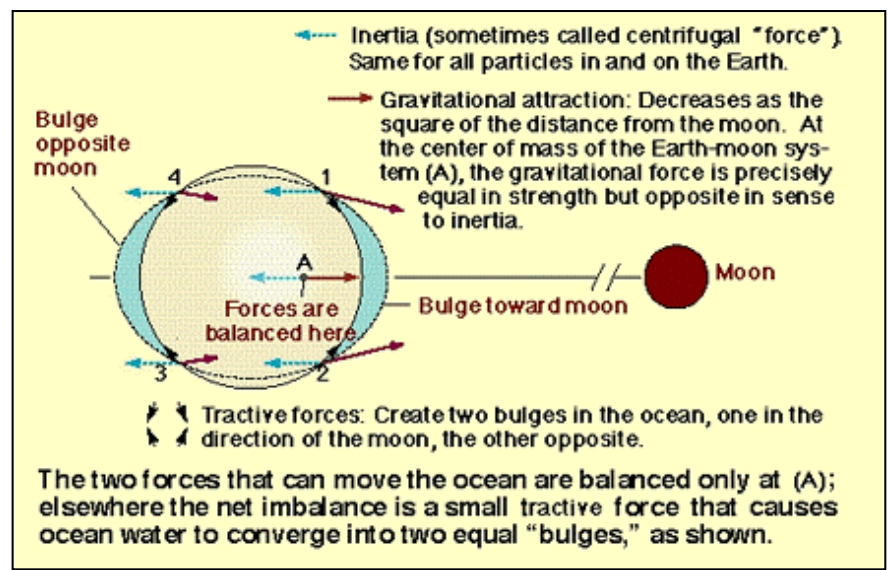

Source: O. Siddiqui and R. Bedard [30]

Fig. 4.3. Tide-generating forces based on earth-moon interactions.

In deep water, the wave power spatial flux (in $\mathrm{kW} / \mathrm{m}$ of wave front crest) is given by significant wave height $\left(\mathrm{H}_{\mathrm{s}}\right.$ in $\left.\mathrm{m}\right)$ and the peak wave period $\left(\mathrm{T}_{\mathrm{p}}\right.$ in sec). Based on these two parameters, the incident wave power ( $\mathrm{J}$ in $\mathrm{kW} / \mathrm{m}$ of wave crest length) associated with each sea state record is estimated by the following equation:

$$
\mathrm{J}=0.42 \times\left(\mathrm{H}_{\mathrm{s}}\right)^{2} \times \mathrm{T}_{\mathrm{p}}
$$

It is significant to note that wave power varies with the square of wave height - that is, a wave whose height is doubled generates four times as much power.

The power of a tidal current is given by the following equation:

$$
P_{\text {water }}=1 / 2 \mathrm{r} \mathrm{A} \mathrm{V}^{3}(\mathrm{~W})
$$

where A is the cross- sectional area of flow intercepted by the turbine device $\left(\mathrm{m}^{2}\right), \mathrm{r}$ is the water density $\left(\mathrm{kg} / \mathrm{m}^{3}\right)$ and $\mathrm{V}$ is current velocity speed $(\mathrm{m} / \mathrm{s})$. The current velocity $\mathrm{V}$ varies in a precisely predictable manner as an additive function of period of the different sinusoidal tidal components.

\subsubsection{Wave Project Results}

\subsubsection{U.S. Wave Energy Resources}

An ideal site to deploy, operate and maintain an offshore wave energy power plant must have many attributes. First and foremost is a sufficient native energy and energy spectra 
potential. ${ }^{1}$ The U.S. regional wave regimes and the total annual incident wave energy for each of these regimes are shown in Figure 4.4 (the total U.S. available incident wave energy flux is about 2,300 TWh/yr).

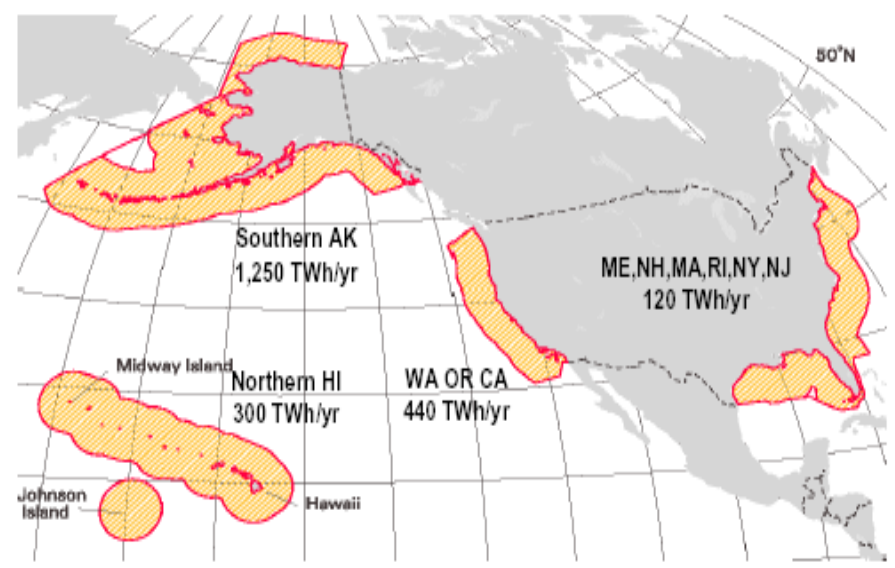

Source: O. Siddiqui and R. Bedard [30]

Fig. 4.4. U.S. energy resources

\subsubsection{Feasibility Definition Study Sites}

Site attributes characterized by the Project Team included offshore bathymetry ${ }^{2}$ and seafloor surface geology, robustness of the coastal utility grid, regional maritime infrastructure for both fabrication and maintenance, conflicts with competing uses of sea space and existence of other unique characteristics that might minimize project development costs (e.g., existing ocean outfall easements for routing power cable and shore crossing).

\begin{tabular}{|l|c|c|c|c|c|}
\hline & HI & OR & CA & Mass & Maine \\
\hline County & Oahu & Douglas & SF & Cape Cod & Cumberland \\
\hline Grid I/C & $\begin{array}{c}\text { Wai- } \\
\text { manalo } \\
\text { Beach }\end{array}$ & Gardner & $\begin{array}{c}\text { Wastewater } \\
\text { Plant }\end{array}$ & Well Fleet & $\begin{array}{c}\text { Old Orchard } \\
\text { Beach S/S }\end{array}$ \\
\hline $\begin{array}{l}\text { Average Annual J } \\
(\mathrm{kW} / \mathrm{m})\end{array}$ & 15.2 & 21.2 & $11.2^{1}$ & 13.8 & 4.9 \\
\hline Depth (m) & 60 & 60 & 30 & 60 & 60 \\
\hline Distance from Shore & 2 & 3.5 & 13 & 9 & 9 \\
\hline Cable Landing & $\begin{array}{c}\text { Makai } \\
\text { Pier }\end{array}$ & $\begin{array}{c}\text { IPP out } \\
\text { flow pipe }\end{array}$ & $\begin{array}{c}\text { Water out } \\
\text { flow }\end{array}$ & $\begin{array}{c}\text { Dir } \\
\text { Drill }\end{array}$ & Dir Drill \\
\hline
\end{tabular}

Source: O. Siddiqui and R. Bedard [30]

${ }^{1}$ Sited within the marine sanctuary exclusionary zone

Table 4.2 Estimated Performances of Pilot Demonstration Plants

\footnotetext{
${ }_{2}^{1}$ Energy as function of wave height and wave period or frequency

${ }^{2}$ Bathymetry is the depth of the seafloor below mean water height (i.e., the inverse of a topographic map)
} 
Table 4.2 identifies the site selected in each of the five states that participated in the study, and also provides a few key characteristics of each selected site.

\subsubsection{Feasibility Study - WEC Devices:}

Twelve companies responded to EPRI's request for information. An initial screening considered two key issues: 1) technology readiness (i.e. readiness of device for demonstration in the 2006 time period); and 2) survivability in adverse conditions (i.e., sufficiency of technical information provided by the device manufacturer to prove the survivability in storm conditions). The eight devices that passed the initial screening criteria are shown in Table 4.3.

These eight devices were then assessed with the objective of determining any critical issues and recommending RD\&D needed to achieve technological readiness for an at sea demonstration. As a result of this assessment, the eight devices were grouped into one of three levels of development categories:

- Level 1 - Development complete and full-scale testing in the ocean underway

- Level 2 - Development near complete. Only deployment, recovery and mooring issues are yet to be validated. There are funded plans for full-scale at sea testing.

- Level 3 - Most critical RD\&D issues are resolved. Additional laboratory and sub-scale testing, simulations and systems integration work is needed prior to finalization of the full-scale design. There are no funded plans for full-scale at sea testing.

\begin{tabular}{|l|c|c|c|c|c|}
\hline & $\begin{array}{c}\text { Length } \\
(\mathbf{m})\end{array}$ & $\begin{array}{c}\text { Width } \\
(\mathbf{m})\end{array}$ & $\begin{array}{c}\text { Power } \\
\mathbf{( k W )}\end{array}$ & Type & Rating \\
\hline $\begin{array}{l}\text { Ocean Power } \\
\text { Delivery }\end{array}$ & 120 & 4.6 & 153 & $\begin{array}{c}\text { Floating } \\
\text { Attenuator }\end{array}$ & 1 \\
\hline Energetech & 25 & 35 & 259 & $\begin{array}{c}\text { OWC - Bottom } \\
\text { Terminator }\end{array}$ & 2 \\
\hline Wave Dragon & 150 & 260 & 1369 & $\begin{array}{c}\text { Floating } \\
\text { Overtopping }\end{array}$ & 2 \\
\hline Wave Swing & 9.5 & 9.5 & 351 & $\begin{array}{c}\text { Bottom Point } \\
\text { Absorber }\end{array}$ & 2 \\
\hline Wave Bob & 16 & 15 & 131 & $\begin{array}{c}\text { Floating Point } \\
\text { Absorber }\end{array}$ & 3 \\
\hline $\begin{array}{l}\text { Aqua- } \\
\text { Energy }\end{array}$ & 6 & 6 & 17 & $\begin{array}{c}\text { Floating Point } \\
\text { Absorber }\end{array}$ & 3 \\
\hline OreCON & 32 & 32 & 532 & Floating OWC & 3 \\
\hline $\begin{array}{l}\text { Ind Natural } \\
\text { Resources Inc }\end{array}$ & 5.4 & 5.4 & 112 & $\begin{array}{c}\text { Bottom Point } \\
\text { Absorber }\end{array}$ & 3 \\
\hline
\end{tabular}

Source: O. Siddiqui and R. Bedard [30]

${ }^{1}$ Based on Oregon average annual wave energy resource

Table 4.3. Estimated Performance of Pilot Demonstration Plants 
At the time of EPRI's analysis (March 2004), only one WEC device manufacturer had attained a Level 1 technology readiness status - Ocean Power Delivery with its Pelamis device.

\subsubsection{Demonstration-Scale Plant Design - Oregon Example}

Demonstration-scale (as well as commercial-scale) designs were based on the Ocean Power Delivery (OPD) Pemamis WEC device for the five sites listed in Table 4.2. The Pelamis WEC device consists of four cylindrical steel sections, which are connected by three hydraulic power conversion modules (PCM). Total length of the device is $120 \mathrm{~m}$ and device diameter is $4.6 \mathrm{~m}$. Figure 4.5 illustrates the device being tested off the Scottish coast.

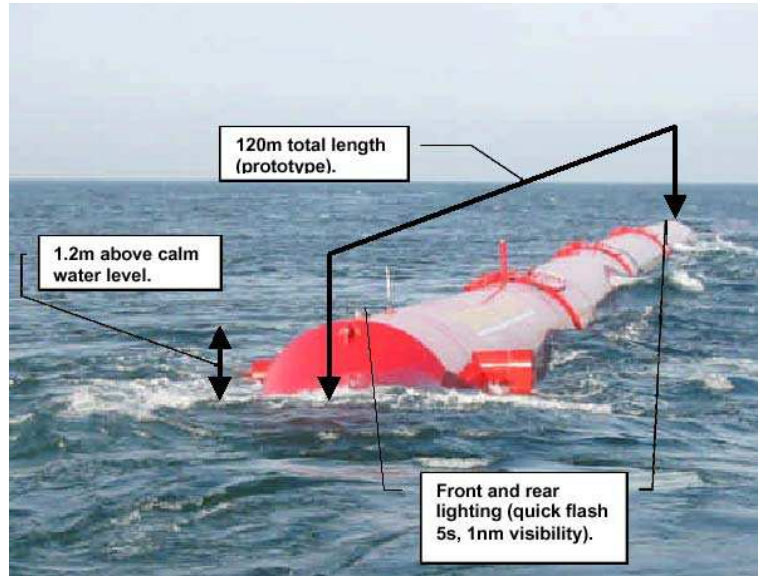

Source: O. Siddiqui and R. Bedard [30]

Fig. 4.5. OPD Pelamis WEC device.

A second San Francisco, CA design based on the Energetech OWC WEC device depicted in Fig. 4.6 has also been tested.

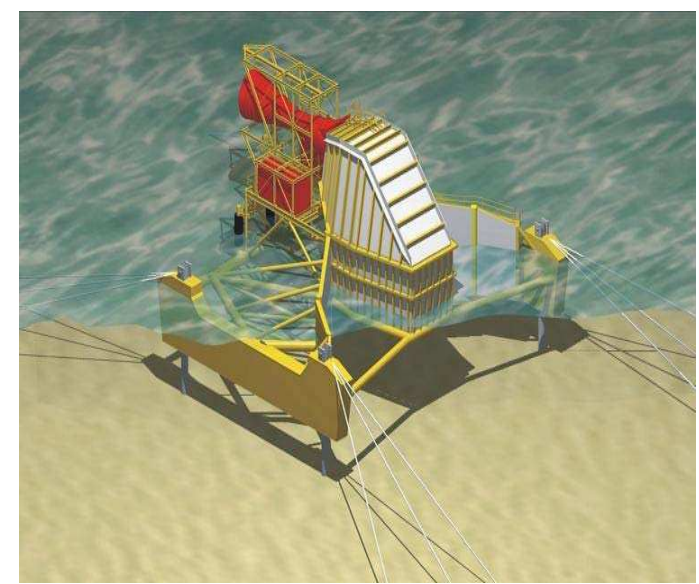

Source: O. Siddiqui and R. Bedard [30]

Fig. 4.6. Energetech WEC device. 
The estimated performance of the single unit demonstration plant at each of the five sites is shown in Table 4.4.

\begin{tabular}{|l|c|c|c|c|c|}
\hline & HI & OR & CA 1 & Mass & Maine \\
\hline Device Rated Capacity (kW) & 750 & 750 & 750 & 750 & 750 \\
\hline $\begin{array}{l}\text { Annual Energy Absorbed } \\
\text { (MWh/yr) }\end{array}$ & 1,989 & 1,472 & 1,229 & 1,268 & 426 \\
\hline $\begin{array}{l}\text { Annual Energy Produced } \\
\text { (MWh/yr) }\end{array}$ & 1,663 & 1,001 & 835 & 964 & 290 \\
\hline $\begin{array}{l}\text { Average Electrical Power } \\
\text { (kW) }\end{array}$ & 180 & 114 & 95 & 98 & 33 \\
\hline $\begin{array}{l}\text { Number of Homes Powered } \\
\text { by Plant }\end{array}$ & 180 & 114 & 95 & 98 & 33 \\
\hline
\end{tabular}

Source: O. Siddiqui and R. Bedard [30]

${ }^{1}$ Energetech site numbers: $1000 \mathrm{~kW}, 1643 \mathrm{MWh} / \mathrm{yr}, 1264 \mathrm{MWh} / \mathrm{yr}$, and $144 \mathrm{~kW}$ respectively

Table 4.4. Estimated Performance of Pelamis Pilot Demonstration Plants

\subsubsection{Commercial-Scale Plant Design - Oregon Example:}

The commercial system uses a total of 4 clusters, each one containing 45 Pelamis units (i.e., 180 total Pelamis WEC devices), connected to sub-sea cables. Each cluster consists of 3 rows with 15 devices per row. The other state designs are organized in a similar manner with 4 clusters. The number of devices per cluster varies such that each plant produces an annual energy output of 300,000 $\mathrm{MWh}$ /yr. The electrical interconnection of the devices is accomplished with flexible jumper cables, connecting the units in mid-water. The introduction of 4 independent sub-sea cables and the interconnection on the surface provides some redundancy in the wave farm arrangement.

The estimated performance of the commercial-scale plant at each of the five sites is shown in Table 4.5.

\begin{tabular}{|l|c|c|c|c|c|}
\hline & HI & OR & CA & Mass & Maine \\
\hline $\begin{array}{l}\text { Device Rated Capacity } \\
(\mathrm{kW})\end{array}$ & 500 & 500 & 500 & 500 & 500 \\
\hline $\begin{array}{l}\text { Annual Energy Absorbed } \\
(\mathrm{MWh} / \mathrm{yr})\end{array}$ & 1,989 & 1,997 & 1,683 & 1,738 & 584 \\
\hline $\begin{array}{l}\text { Annual Energy Produced } \\
\text { (MWh/yr) }\end{array}$ & 1,663 & 1,669 & 1,407 & 1,453 & 488 \\
\hline $\begin{array}{l}\text { Average Electrical Power } \\
\text { at Busbar (kW) }\end{array}$ & 191 & 191 & 161 & 166 & 56 \\
\hline $\begin{array}{l}\text { Number of OPD Pelamis } \\
\text { Units Needed for 300,000 } \\
\text { MWh/yr }\end{array}$ & 180 & 180 & 213 & 206 & 615 \\
\hline $\begin{array}{l}\text { Number of Homes } \\
\text { Powered by Plant }\end{array}$ & 34,000 & 34,000 & 34,000 & 34,000 & 34,000 \\
\hline
\end{tabular}

Source: O. Siddiqui and R. Bedard [30]

Table 4.5. Estimated Performance of Pelamis Commercial Plants 
The device rated capacity has been derated from $750 \mathrm{~kW}$ in the demonstration plant to $500 \mathrm{~kW}$ for the commercial plant. The performance assessment of the demonstration plants shows that the PCMs are overrated and reducing the rated power to $500 \mathrm{~kW}$ per device would yield a significant cost reduction and only a relatively small decrease in annual output (attributed to the fact that the U.S. sites have a lower energy level than UK sites for which the device was originally developed).

\subsubsection{Learning Curves and Economics:}

The costs and cost of electricity shown in the previous section are for the first commercial scale wave plant. Learning through production experience reduces costs - a phenomenon that follows a logarithmic relationship such that for every doubling of the cumulative production volume, there is a specific percentage drop in production costs. The specific percentage used in this study was $82 \%$, which is consistent with documented experience in the wind energy, photovoltaic, shipbuilding, and offshore oil and gas industries.

The industry-documented historical wind energy learning curve is shown as the top line in Figure 4.7 [31]. The cost of electricity is about 4 cents/kWh in 2004 U.S. dollars based on 40,000 MW of worldwide installed capacity and a good wind site. The lower and higher bound cost estimates of wave energy are also shown in Figure 4.7. The $82 \%$ learning curve is applied to the wave power plant installed cost but not to the operation and maintenance part of cost of electricity (hence the reason that the three lines are not parallel).

Figure 4.7 shows the cost of wave-generated electricity: low band (bottom curve), upper band (middle curve); and wind generated electricity (top curve) at equal cumulative production volume under all cost estimating assumptions for the wave plant. It shows that the cost of wave-generated electricity is less than wind-generated electricity at any equal cumulative production volume under all cost estimating assumptions for the wave plant. The lower capital cost of a wave machine (compared to a wind machine) more than compensates for the higher O\&M cost for the remotely located offshore wave machine. A challenge to the wave energy industry is to drive down O\&M costs to offer even more economic favorability and to delay the crossover point shown at greater than 40,000 MW.

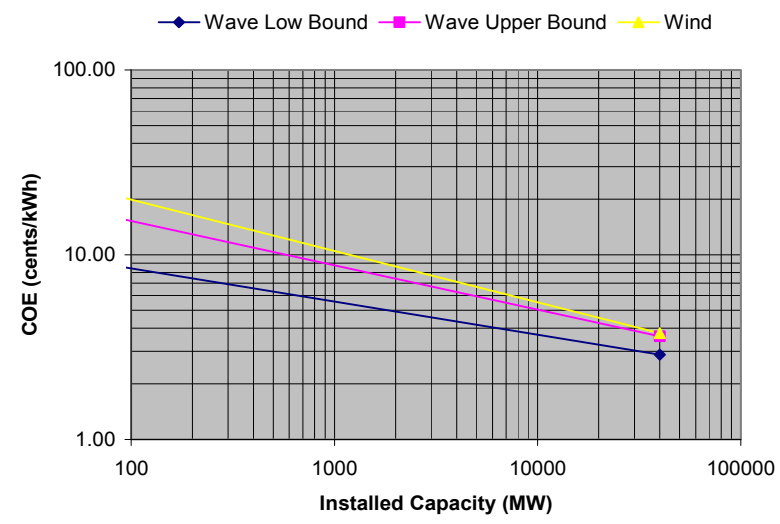

Source: O. Siddiqui and R. Bedard [30]

Fig. 4.7. Electrical interconnection of demo-plant - Oregon example. 
The techno-economic forecast made by the Project Team is that wave energy will first become commercially competitive with the current 40,000 MW installed land-based wind technology at a cumulative production volume of 15,000 MW or less in Hawaii and northern California, about 20,000 MW in Oregon and about 40,000 MW in Massachusetts. This forecast was made on the basis of a 300,000 MWh/yr (nominal $90 \mathrm{MW}$ at 38\% capacity factor) Pelamis WEC commercial plant design and application of technology learning curves. Maine was the only state in the study whose wave climate was such that wave energy may never be able to economically compete with a good wind energy site.

In addition to economics, there are other compelling arguments for investing in offshore wave energy technology. First, with proper sitting, converting ocean wave energy to electricity is believed to be one of the most environmentally benign ways to generate electricity. Second, offshore wave energy offers a way to minimize the 'Not In My Backyard' (NIMBY) issues that plague many energy infrastructure projects, from nuclear to coal and to wind generation. Because these devices have a very low profile and are located at a distance from the shore, they are generally not visible. Third, because wave energy is more predictable than solar and wind energy, it offers a better possibility than either solar or wind of being dispatch able and earning a capacity payment.

A characteristic of wave energy that suggests that it may be one of the lowest cost renewable energy sources is its high power density. Processes in the ocean concentrate solar and wind energy into ocean waves making it easier and cheaper to harvest. Solar and wind energy sources are much more diffuse, by comparison.

Since a diversity of energy sources is the bedrock of a robust electricity system, to overlook wave energy is inconsistent with national needs and goals. Wave energy is an energy source that is too important to overlook.

\subsection{Recent Progress in Offshore Renewable Energy Technology Development}

Interest in marine renewable energy is at an all-time high, and prospects for ocean-based renewable energy development look brighter all the time. The recent progress in offshore renewable energy technology development is now examined and potential markets for tidal power, wave energy conversion, and offshore wind are considered. The analysis of market potentials for offshore renewable technology is based solely on identified projects. Therefore, the forecasts are relatively conservative, as the prospective markets could expand as technological advances are achieved and as regulatory environments improve.

\subsubsection{Tidal Energy}

Historically, tidal projects have been large-scale barrage systems that block estuaries. Within the last few decades, developers have shifted toward technologies that capture the tidally driven coastal currents or tidal stream. The challenge is, "to develop technology and innovate in a way that will allow this form of low density renewable energy to become practical and economic" [22].

Two groups of technologies are in operation or planning; these are tidal current turbines and tidal stream generators. Tidal current turbines are basically underwater windmills. The tidal currents are used to rotate an underwater turbine. First proposed during the 1970s' oil 
crisis, the technology has only recently become a reality. One company, Marine Current Turbines (U.K.) installed the first full-scale prototype turbine $(300 \mathrm{~kW})$ off Lynmouth in Devon, U.K. in 2003. Shortly thereafter, the Norwegian company Hammerfest Støm installed their first prototype device.

There are a great number of sites suitable for tidal current turbines. As tidal currents are predictable and reliable, tidal turbines have advantages over offshore wind counterparts. The ideal sites are generally within $1 \mathrm{~km}$ of the shore in water depths of $20-30 \mathrm{~m}$.

Tidal stream generators use the tidal stream to generate power from, for example, the raising and lowering of a hydraulic arm. Several promising devices are at the advanced stage of development. For example, the UK firm, The Engineering Business Ltd. has developed and tested a simple concept of placing hydrofoils in tidal stream to produce an oscillatory motion in the vertical or horizontal plane. The device, known as the Stingray ${ }^{\mathrm{TM}}$ Tidal Current Generator, "transforms the kinetic energy of the moving water into hydraulic power, which turns a generator by means of a hydraulic motor" [22].

\subsubsection{Tidal Forecasts}

It is anticipated that multi-megawatt installations will emerge by the end of the decade (Figure 4.8). By 2008, a forecast of $14.8 \mathrm{MW}$ installed capacity was expected with $65 \%$ of the capacity in the United Kingdom. Norway, which already has installed capacity, will be the second dominant player, but lacks defined projects over the next 5 years. Other countries (Canada, France and United States) have a minor role, but could expand prototype devices as the devices progress. Canada and the United States have potential locations, some of which are under negotiation for U.K. tidal generation technology [23].

Almost $70 \%$ of forecast capacity for 2008 was anticipated from tidal current turbines with approximately $30 \%$ from tidal stream generators. Tidal current turbines represent an extremely important sector for offshore renewables as there are several well-developed devices and such technology, once proven, could be installed in large numbers in the near future. However, a lack of identified projects distorts the forecast near the end of the 5-year period, precisely when significant projects could materialize.

It is conceivable that tidal current turbines such as those of Marine Current Turbines or Hammerfest Støm could eventually be installed in large projects comparable in size to offshore wind farms.

With fewer announced projects, tidal stream generators have a lower forecast. Many of the devices are at earlier stage of design. One system that is generating much interest and has potential is the 'Stingray' device, designed and built by experienced offshore engineers [25]. Capital expenditures for tidal energy are forecast at \$35 million over the next five-year period. The U.K. is the biggest market with \$23 million of expenditures forecast to 2008 . Forecasts for Norway at a level of $\$ 10$ million of expenditures over the same period are anticipated. Successful projects could lead to further development later in the period and beyond [23]. Several projects await financial support and could significantly impact the installed capacity as the projects are in excess of $100 \mathrm{MW}$. 
Revised global estimates for capital expenditure in tidal power technology is indicated in Figure 4.8 .

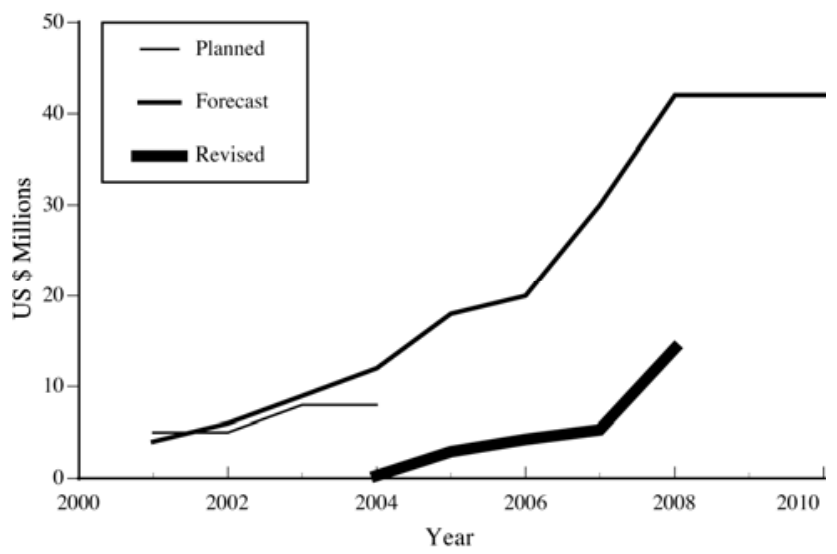

Source: A. T. Jones and A. Westwood [32]

Fig. 4.8. Revised global estimates of capital expenditure in tidal power technology (modified from [24]).

\subsubsection{Projects}

Shihwa Lake Tidal Power Plant, Korea: Korea has a plentiful tidal and tidal current energy resource. Under construction is a single stream style generator at Ansan City's Shiswa Lake, which will have a capacity of $252 \mathrm{MW}$, comprised of 12 units of 21MW generators. Annual power generation, when completed in 2008, was projected at 552 million $\mathrm{kWh}$. If successful, this project will surpass La Rance (France) as the largest tidal power plant in the world. Korea is also planning a tidal current power plant in Uldol-muk Strait, a restriction in the strait where maximum water speed exceeds $6.5 \mathrm{~m} / \mathrm{s}$. The experimental plant will utilize helical or "Gorlov" turbines developed by GCK Technology [26].

Yalu River, China: By creating a tidal lagoon offshore, Tidal Electric has taken a novel approach to resolve environmental and economic concerns of tidal barrage technology [27]. Due to the highly predictive nature of the ocean tides, the company has developed simulation models with performance data from available generators to optimize design for particular locations. The recent announcement of a cooperative agreement with the Chinese government for ambitious $300 \mathrm{MW}$ offshore tidal power generation facilities off Yalu River, Liaoning Province allows for an engineering feasibility study to be undertaken.

Tidal Electric also has plans under consideration for United Kingdom-based projects in Swansea Bay (30 MW), Fifoots Point 930 MW), and North Wales (432 MW).

\subsubsection{Wave Energy}

The true potential of wave energy will only be realized in the offshore environment where large developments are conceivable. Nearly 300 concepts for wave energy devices have been proposed. 
Modular offshore wave energy devices that can be deployed quickly and cost effectively in a wide range of conditions will accelerate commercial wave energy. In the coming decade, wave energy will become commercially successful through multiple-unit projects.

Opportunities for expansion of offshore market are expected to increase. This is because the growth of shoreline wave energy devices will be increasingly limited by the low number of available sites and by high installation costs.

Deployment costs for shoreline wave energy devices are very high because they are individual projects and economies of scale are therefore not applicable. The site-specific demands of shoreline wave energy devices mean a further restriction of growth in this sub-sector. Whereas an offshore 50-MW wave farm is conceivable, and will in time be developed, no shoreline wave energy converter can offer such potential for deployment in this way. As such, individual coastal installations are expected to be few and far between [23].

Shoreline wave energy will, however, continue to be relevant, with approximately 25 percent of the forecast capacity over the next five years. The average unit capacity is generally higher than existing offshore technology. Individual devices can be very effective, especially for remote or island communities where, for example, an individual unit of $4 \mathrm{MW}$ could have a big impact [23].

Offshore locations offer greater power potential than shoreline locations. Shoreline technologies have the benefit of easy access for maintenance purposes, whereas offshore devices are in most cases more difficult to access. Improvements in reliability and accessibility will be critical to the commercial success of the many devices currently under development [23].

Most wave energy projects to date have been small, and few are connected to a power grid. Shoreline devices offer the advantage of easier access to a grid. For offshore devices, meeting this need will be challenging and costly, although not prohibitively so.

\subsubsection{Wave Energy Forecast}

Wave is a most promising sector over the 2004-2008 period and into the long-term future (Figure 4. 9).

The development process for wave energy can be looked at in three phases. First, smallscale prototype devices, typically with low capacity, will be deployed. During the second stage, outside funding from government or private investors is possible for the most promising devices. The final stage is the production of full-scale, grid-connected devices that will in some cases be deployable in farm style configurations.

The United Kingdom is expected to be the dominant player over the next five years. In comparison with other countries, the UK has forecast capacity every year, whereas to 2008, installations elsewhere are more intermittent. Australia, Portugal, and Denmark are the next most significant markets and have several projected installations, but they lag far behind the UK. The United Kingdom government has shown reasonable levels of support, which have injected many technologies with valuable grants. The result is a number of advanced wave energy. Future prospects are for deployment of prototype devices. Coupled with a world- 
class natural resource, the United Kingdom could be the undisputed world leader in wave energy by 2008. Prospects after 2008 are even brighter [23].

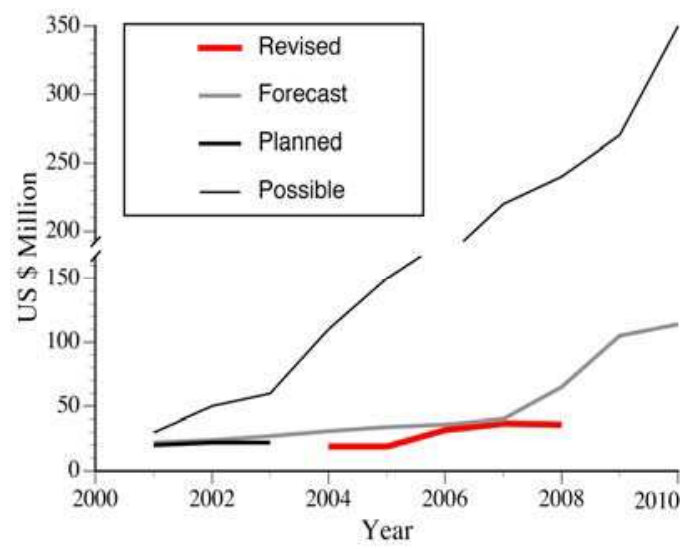

Source: A. T. Jones and A. Westwood [32]

Fig. 4.9. Revised estimates for capital expenditure in wave energy conversion technology. (modified from [24]).

The United States market shows encouraging levels of interest in wave technology; however, the market will be affected by the lack of positive government involvement [23].

\subsubsection{Offshore Wind}

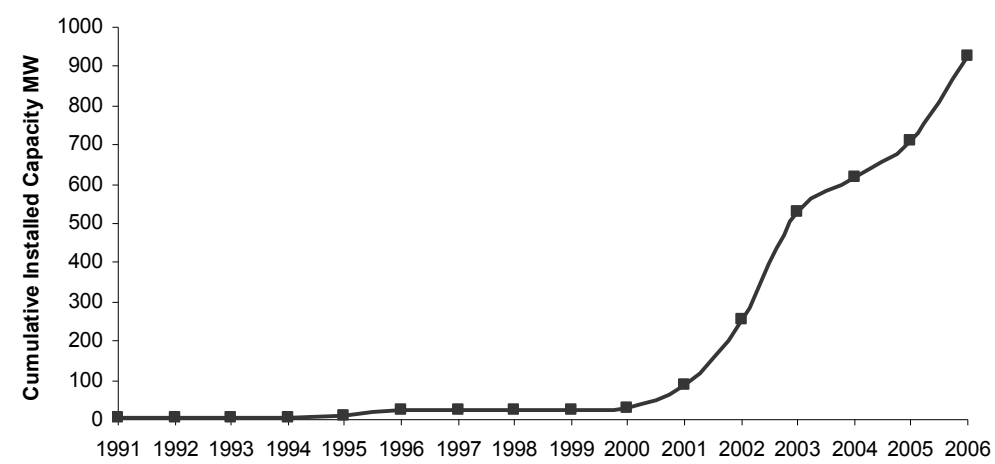

Source: Douglas-Westwood Ltd

Fig. 4.10. Cumulative worldwide offshore wind capacity

The total global offshore wind capacity forecast for installation between 2006 and 2010 stands at 7.4 GW (see Figures 4.10, 4.11). The UK is the world's largest market for the fiveyear period 2005-2010. The UK's prospects are expected to be twice those of Germany for this period, although the German market at $1.1 \mathrm{GW}$ is still the second largest in the world. 
Long-term prospects are excellent off Germany but in the short and mid-term future the industry has much to overcome. Denmark has only two main projects planned for completion by the end of the decade with 200 MW each at Horn Rev and Nysted that are now making progress. The Netherlands has just two projects that were commissioned in 2006 and 2007. No firm prospects have emerged from the last licensing round but long-term potential is there.

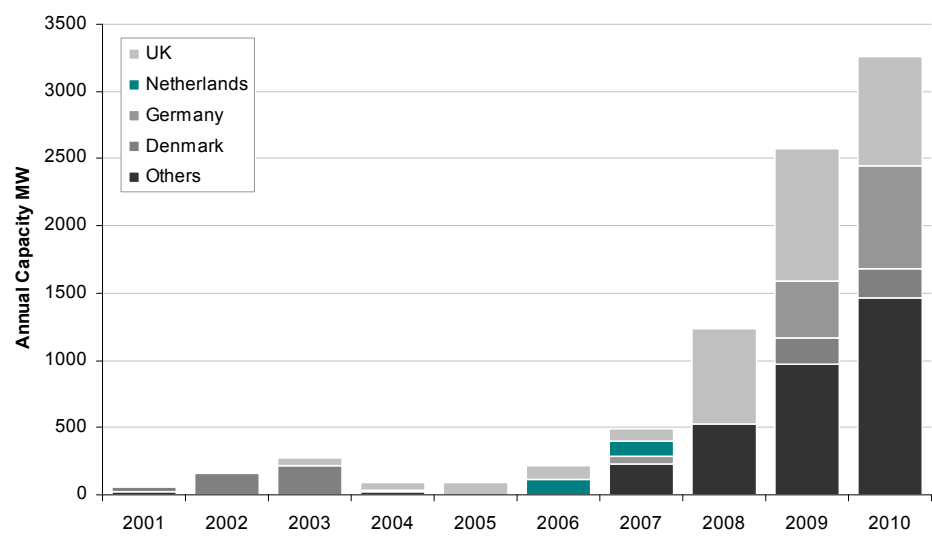

Source: Douglas-Westwood Ltd

Fig. 4.11. Forecast global offshore wind capacity

Technological progress is extremely important for the industry, and will drive developments. As better technology is implemented, large strides in capacity will be achieved using proportionally fewer turbines. For example, up to 1,225 turbines will be installed by 2010. Turbine capacity is increasing, from 2000-2003 the average turbine size was $2 \mathrm{MW}$, current projects are using $3 \mathrm{MW}$ machines and the industry is pushing development of 5 MW turbines for installations from 2009. Prototype installations of these next-generation turbines have already taken place and the first two offshore units were commissioned off the UK at the Beatrice project in 2006.

Long-term signals are good for the UK market, whereas an air of uncertainty hangs over Germany despite its very promising future forecast. The United Kingdom's development is gradual, whereas Germany's depends on large, technologically challenging projects. Denmark's five-year forecast is disappointing, with only two projects scheduled for commissioning in the period, one in 2009 and one in 2010. Although the country showed initial promise for offshore development, a lack of government commitment has been harmful to the industry here. There are no firm plans for future projects after the coming two, so long term prospects are uncertain.

Offshore wind has a potentially large market in North America. Although the United States has considerable offshore wind potential, regulatory uncertainty is a source of concern. The United States has a significant number of projects in the planning stages [29]. These projects, many of which are very speculative, are not expected to arise until the end of the decade. 
For the entire marine renewables sector, 7,500 MW of installed capacity is projected between 2006 and 2010 . Some $98 \%$ of that capacity is in the form of offshore wind farms. Wind farms installed capacity was $213 \mathrm{MW}$ in 2006. By 2010, this will grow to 3,200 MW - over a tenfold growth within five-years. The value of the market over the next five-years is projected at $\$ 16$ billion.

Wave and tidal power will only be a small percentage of the total expenditure on offshore renewables, of the order of $\$ 150$ million in total expenditure between them. However, wave and tidal power currently attract higher expenditures per megawatt. This indicates higher costs of the immature developing industries. These costs will fall as time goes by and the industries progresses. The leading devices should be comparable with, and in some cases more competitive than offshore wind, by the end of the decade.

The dominance of offshore wind does not mean wave and tidal energy are not important, they are just less well developed, and the industry is much younger. If wave and tidal were compared to offshore wind market data from ten years ago, their market share would be much higher. Offshore wind is booming at present. From around 2010, wave and tidal could begin to see this rapid growth.

\subsection{Role of TIDAL Power In The United Kingdom to reduce greenhouse gas emissions}

Sections 4.6 4.13 discusses the role of Tidal Power in the UK in fulfilling the UK's requirements for reducing greenhouse gas emissions. Generating electricity from tidal range of the Severn Estuary has the potential to generate some $5 \%$ of UK electricity from a renewable indigenous resource.

These Sections focus primarily on the proposed Severn Barrage considering potential benefits, conditions for sustainable development, energy policy context and compliance with environment legislation. UK tidal resource is reviewed: stream resource and tidal range resource. The top tidal range and tidal stream sites in the UK with the resource (in TWh/year) are indicated.

A feasibility study for Tidal Range development in the Mersey Estuary is also summarized and other schemes including the Loughor Estuary (Wales), Duddon Estuary (located on the Cumbrian coast) and the Thames Estuary proposals are reported. Also given is a strategic overview of the Severn Estuary resource, electric output and characteristics, carbon emissions (carbon payback and carbon reduction potential) and physical implications of a barrage.

Approximately $40 \%$ of the UK's electricity will have to be generated from renewables (wind, tidal/wave, and plant energy) by 2020 as a result of a legally binding EU target under the Bali Protocol. It is likely to mean a six-fold increase in the amount of onshore wind turbines and a 50 -fold increase in the number of offshore wind turbines. This is because the $20 \%$ target for all renewables by 2020 applies to energy across the board, including transport and heating, where the scope for renewables is less, implying the electric sector must do more. By 2050, the UK is planning to reduce its $\mathrm{CO}_{2}$ emissions by at least $60 \%$ compared with its emissions in 1990. 
A study is underway and is expected to last roughly two years (until January 2010). Under consideration is tidal range, including barrages, lagoons and other technologies, and includes a Strategic Environmental Assessment of plans for generating electricity from the Severn Estuary tidal range to ensure a detailed understanding of its environmental resource recognizing the nature conservation significance of the Estuary. The scheme would use proven technology of a hydroelectric dam but filled by the incoming tide rather than by water flowing downstream. The Severn Estuary has some of the best tidal potential in the world and could more than double the current UK supply of renewable electricity and contribute significantly to targets for renewable energy and $\mathrm{CO}_{2}$ emissions reduction. The scheme would have a capacity of 8640 MW and produce roughly $17 \mathrm{TWh}$ /year with a load factor of 0.22 .

The physics of tidal power: types of tides, semidiurnal tides with monthly variation, diurnal tides with monthly variation, and mixed tides are examined. Variations in output from tidal power due to spring neap cycle is assessed, and technically available tidal energy resource in Europe is also estimated by parametric modeling. Existing tidal energy schemes and sites considered for development worldwide are reviewed. Then, harnessing tidal power (flow or basin, modes of operation and configuration, ebb generation, flood generation, two-way generation and pumping) is indicated. Tidal stream technology that is in the early stages of development but could harness half of the UK's tidal potential is reviewed. The proposed Severn barrage considering tidal resonance in the Severn Estuary, potential benefits, the conditions for sustainable development and energy policy context, compliance with environment legislation and UK tidal resource is also reviewed.

The electricity transmission system in the UK in the Severn area is evaluated where system constraints and upgrades and implications of tidal power are considered. The awareness of energy sources (wind, solar, coal, nuclear, gas, tidal/wave and bio-energy) that can generate electricity in the UK is outlined.

Concerns on Environment Impact considering the protected status of the Severn Estuary (Habitats Directive and Nature 2000), the Birds Directive defining biodiversity objectives, habitats and ecology are considered. Potential carbon savings for the two Severn proposals are then reviewed.

A consensus view is given on tidal power in the UK (tidal stream long-term potential \{policy improvements, strategic planning and consenting\}, tidal lagoons, and tidal barrages). Conditions for a sustainable Severn barrage (energy policy context, ensuring public interest, apportionment of risks and benefits, avoiding short-termism, regional impacts and priorities) complying with environmental legislation (applying environmental limits and providing compensatory habitats) is given. The final decision on whether this project that will contribute to the UK fulfilling its greenhouse gas emission targets will be given the go-ahead is reviewed.

\subsubsection{Tidal Power}

Tidal Power including the physics of tidal power (types of tide: diurnal tides with monthly variation, mixed tides, major periodic component, the resource), European energy potential, 
existing tidal energy schemes, world-wide energy potential, and harnessing tidal power (that includes flow or basin, existing tidal energy schemes, modes of operation and configuration, adaptation of tide-generated to grid network requirements, etc.) is considered first (see Reference [1]). A number of different barrage options worldwide are then summarized. These options include barrages in UK; La Ranch Tidal Barrage in France; and former Soviet Union, China, South Korea, India, Canada, and others. Development trends, economics, institutional constraints and development are discussed.

\subsubsection{Physics of Tidal Power}

Tidal energy is derived from the gravitational forces of attraction that operate between a molecule on the earth and moon, and between a molecule on the earth and sun. The force is $\mathrm{f}=\mathrm{KM} \mathrm{m} \mathrm{/} \mathrm{d}^{2}$, where $\mathrm{m}$ is the mass of the molecule on the earth, $\mathrm{M}$ is the mass of the moon or sun, $\mathrm{d}$ is the distance between the bodies, and $\mathrm{K}$ is the universal constant of gravitation. The attractive force exerted by the sun is about 2.17 times less than that due to the moon due to the mass and much greater distance that separates the earth and sun. As the earth rotates, the distance between the molecule and the moon will vary. When the molecule is on the dayside of the earth relative to the moon or sun, the distance between the molecule and the attracting body is less than when the molecule is on the horizon, and the molecule will have a tendency to move away from the earth. Conversely, when the molecule is on the night side of the earth, the distance is greater and the molecule will again have a tendency to move away from the earth. The separating force thereby experiences two maxims each day due to the attracting body. It is also necessary to take into the account the beating effect caused firstly by difference in the fundamental periods of the moon- and sun-related gravitational effects, which creates the so-called spring and neap tides, and secondly the different types of oscillatory response affecting different seas. If the sea surface were in static equilibrium with no oscillatory effects, lunar forces, which are stronger than solar forces, would produce tidal range that would be approximately only $5.34 \mathrm{~cm}$ high.

\subsubsection{Types of Tide}

Tidal phenomena are periodic. The exact nature of periodic response varies according to the interaction between lunar and solar gravitation effects, respective movements of the moon and sun, and other geographical peculiarities. There are three main types of tide phenomena at different locations on the earth.

- Semidiurnal Tides with Monthly Variation: This type of tide has a period that matches the fundamental period of the moon (12 hr $25 \mathrm{~min}$ ) and is dominated by lunar behavior. The amplitude of the tide varies through the lunar month, with tidal range being greatest at full moon or new moon (spring tides) when the moon, earth, and sun are aligned. At full moon, when moon and sun have diametrically opposite positions, the tides are highest, because the resultant center of gravity of moon and earth results in the earth being closer to the sun, giving a higher gravity effect due to the sun. At new moon, maximum tidal range is less. Minimum tides (neap tides) occur between the two maxims and correspond to the half-moon when the pull of the moon and sun is in quadrature, i.e., the resultant pull is the vector sum of the pull due to moon and sun, respectively. In 
this case, the resultant gravitation force is a minimum. A resonance phenomenon in relation to the $12 \mathrm{hr}-25$-min periods characterizes tidal range.

- Diurnal Tides with Monthly Variation. This type of tide is found in the China Sea and at Tahiti. The tidal period corresponds to a full revolution of the moon relative to the earth (24 hr- 50-min). The tides are subject to variations arising from the axis of rotation of the earth being inclined to the planes of orbit of the moon around the earth and the earth around the sun.

- Mixed Tides. Mixed tides combine the characteristics of semidiurnal and diurnal tides. They may also display monthly and bimonthly variation. Examples are of mixed tides are those observed in the Mediterranean and at Saigon.

\subsubsection{Major Periodic Components}

The following periodic components in tidal behavior can be identified: (i) a 14-day cycle, resulting from the gravitational field of the moon combining with that of the sun to give maxims and minima in the tides (called spring and neap tides, respectively); (ii) a $1 / 2$ year cycle, due to the inclination of the moon's orbit to that of the earth, giving rise to a period of about 178 days between the highest spring tides, which occur in March and September, (iii) the Saros, a period of 18 2/3 years required for the earth, sun, and moon to return to the same relative positions, and (iv) other cycles, such as those over 1600 years which arise from further complex interactions between the gravitational fields.

Maximum height reached by high water varies in 14-day cycles with seven days between springs (large tide range) and neaps (small tide range). The spring range may be twice that of the neaps. Half-yearly variations are $+/-11 \%$, and over $182 / 3$ years $+/-4 \%$. In the open ocean, the maximum amplitude of the tides is less than $1 \mathrm{~m}$. Tidal amplitudes are increased substantially particularly in estuaries by local effects such as shelving, funneling, reflection, and resonance. The driving tide at the mouth of the estuary can resonate with the natural frequency of tidal propagation up the estuary to give a mean tidal range of over $11 \mathrm{~m}$ in the Severn Estuary, UK and can vary substantially between different points on the coastline ${ }^{3}$ The physics of tidal range is examined by Baker in more depth in [33].

\subsubsection{European Energy Potential}

The amount of energy available from a tide varies approximately with the square of tidal range. The energy available from a tidal power plant would therefore vary by a factor of four (eight for tidal stream) over a spring-neap tide cycle. Typical variation in output from tidal range and tidal stream power in the Severn Estuary due to the spring-neap cycle is indicated in Figures 4.12(a) and 4.12(b), respectively. Approximately 20 suitable regions for development of tidal power worldwide have been identified.

A parametric approach [34] has been used to estimate tidal energy potential for appropriate EU countries (Belgium, Denmark, France, Germany, Greece, Ireland, Portugal, Spain, The Netherlands, and UK). An assessment of all reasonably exploitable sites within the EU with a

\footnotetext{
${ }^{3}$ Tidal range is the tidal height between high-tide and low tide. Typical tidal ranges are Bay of Fundy (Canada) 19.6 m; Granville (France) 16.8 m; La Rance (France) 13.5 m.
} 
mean range exceeding three meters yielded a total energy potential of about $105 \mathrm{TWh} /$ year. This potential is mainly in the UK (50 TWh/year) and France (44 TWh/year), with smaller contributions in Ireland, The Netherlands, Germany and Spain. Technically available resource for tidal energy estimated using parametric modeling is given in Table 4.6.

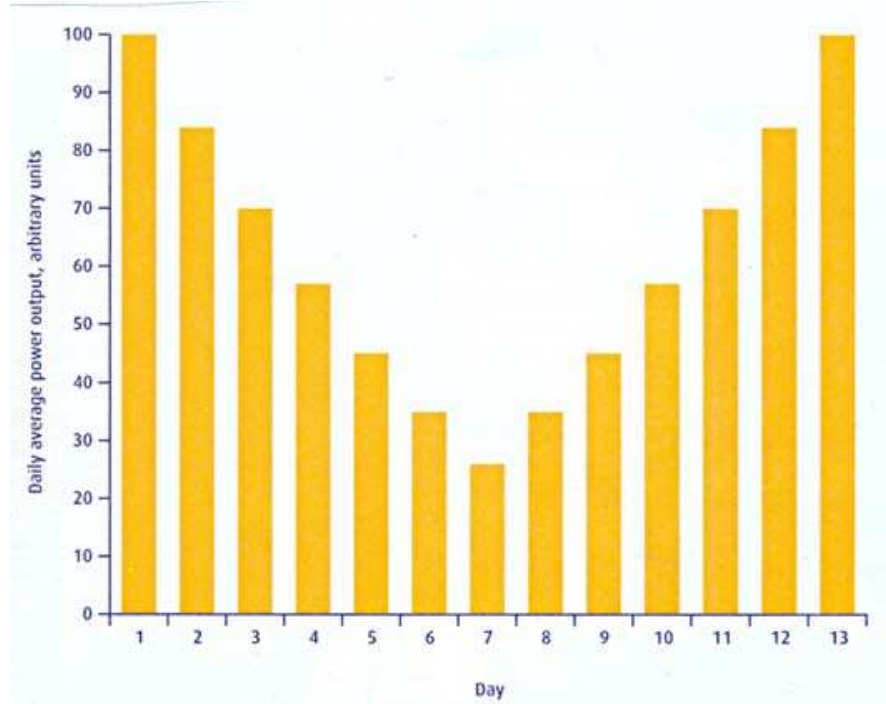

Fig. 4.12(a). Typical variation in output from tidal range power due to spring-neap cycle

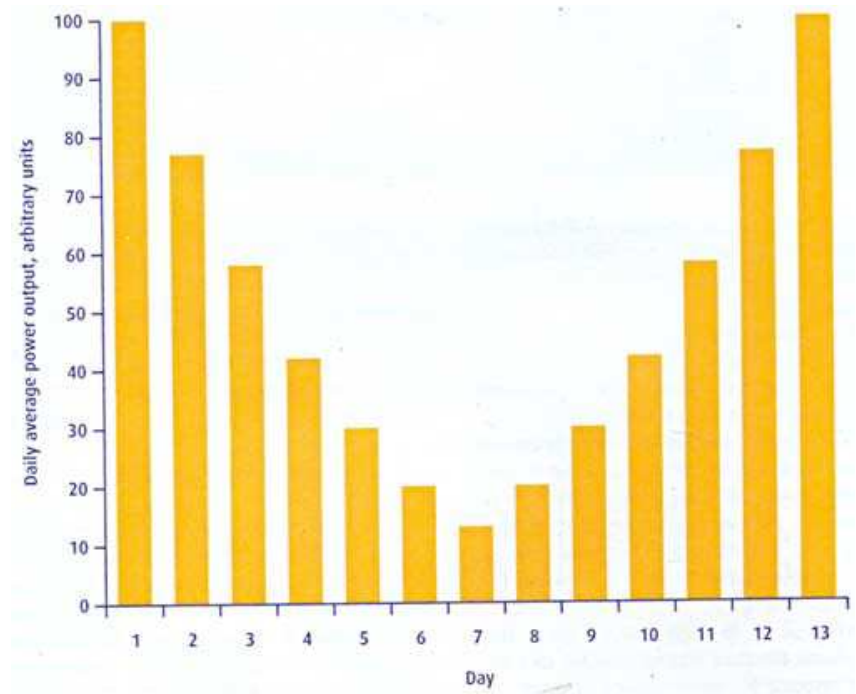

Fig. 4.12(b). Typical variation in output from tidal stream power due to spring-neap cycle. 


\begin{tabular}{|l|c|c|c|}
\hline \multicolumn{1}{|c|}{ Country } & \multicolumn{2}{|c|}{$\begin{array}{c}\text { Technically } \\
\text { Available Tidal } \\
\text { Energy Resource }\end{array}$} & $\begin{array}{c}\text { Percentage } \\
\text { of } \\
\text { European } \\
\text { Tidal } \\
\text { Resource }\end{array}$ \\
\cline { 2 - 3 } & GW & TWh/year & 47.7 \\
\hline United Kingdom & 25.2 & 50.2 & 42.1 \\
\hline France & 22.8 & 44.4 & 7.6 \\
\hline Ireland & 4.3 & 8.0 & 1.8 \\
\hline Netherlands & 1.0 & 1.8 & 0.7 \\
\hline Germany & 0.4 & 0.8 & 0.1 \\
\hline Spain & 0.07 & 0.13 & 0 \\
\hline Other W European & 0 & 0 & 100.0 \\
\hline Total W European & 63.8 & 105.4 & \\
\hline
\end{tabular}

Table 4.6. Technically Available Tidal Energy Resource in Europe Estimated by Parametric Modeling

\subsubsection{Existing Tidal Energy Schemes}

Relatively few tidal power plants have been constructed to date. The first and largest is the $240 \mathrm{MW}$ barrage at La Ranch (France) [35], which was built for commercial production in the 1960s. Other tidal power plants include the 17.8 MW plant at Annapolis (Canada), the 400-kW experimental plant at Kislaya Guba (former Soviet Union), and the 3.2 MW Jiangxia station (China).

\subsubsection{Sites Considered for Development Worldwide}

Economic feasibility of tidal barrage schemes is dependent on the world market price of fossil fuels, interest rates over scheme expected life, and on level of fossil fuel levies based on the carbon content of fuel and electricity not produced by renewable energy sources, etc. Tidal power sites of capacity above 1GW considered for development with installed capacity and approximate annual output include: (i) Argentina San Jose, 6.8GW, $20.0 \mathrm{TWh}$; (ii) Canada Cobequid, 5.34 GW, 14.0 TWh; (iii) Canada Cumberland 1.4 GW, 3.4 TWh; (iv) Canada Shepody, 1.8GW, 4.8 TWh; (v) India Gulf of Cambay, 7.0 GW, 15 TWh; (vi) UK Severn, 8.6 GW, 17 TWh; (vii) USA Knit Arm, 2.9 GW, 7.4 TWh; (viii) USA Turnagain Arm, 6.5 GW, 16.6 TWh; (ix) Former Soviet Union Mezen, 15 GW, 50 TWh; (x) Former Soviet Union Tugur, 10 GW, 27 TWh; and (xi) Former Soviet Union Penzhinskaya, 50 GW, 200 TWh.

\subsubsection{Harnessing Tidal Power (flow or basin, existing tidal energy schemes, modes of operation and configuration, adaptation of tide-generated to grid network requirements)}

Devises include waterwheels; lift platforms, air compressors, water pressurization, etc. Energy can be extracted either directly by harnessing the kinetic energy of a tide flow, or by using a basin to capture potential energy of a rising and falling mass of water. 


\subsubsection{Tidal Flow}

Tide flows have a poor energy density. Theoretical available power $P$ is given by $P=D A V^{3}$, where $D$ is the fluid density, $A$ is the area swept out by the turbine rotor, and $V$ is the undisturbed stream velocity [36]. The energy can be harnessed only with poor maximum efficiency, similar to a windmill, where an efficiency of $59.3 \%$ is possible. Directly harnessing power in this way, however, does not require expensive additional structures.

\subsubsection{Basin}

This method involves constructing a barrage and forming a basin from a natural bay or estuary. Considerable extra cost is incurred, but this is more than outweighed by the extra energy that is extractable. The energy available from a turbine in an effective barrage is one or two orders of magnitude greater than that from a similar size of turbine in a tide stream of, for example, $2 \mathrm{~m} / \mathrm{s}$. The extra cost of constructing the barrage may be only a third of scheme overall cost.

\subsubsection{Modes of Operation and Configuration}

The tide is the only factor that affects the generating activity of a tidal power plant that is programmed to produce maximum output. The output at any given time can be accurately calculated as far in advance as is necessary.

\subsubsection{Single-Action Outflow (Ebb) Generation}

Barrages can use either one basin or a combination of basins, and can operate by ebb, flood, or two-way generation, with or without pumping. The simplest method is ebb generation using a single basin. The basin is permitted to fill through sluices (gated openings). Generation takes place as the basin is emptied via turbines once the tide level has dropped sufficiently. There are two bursts of generation each day.

Typical day-to-day fluctuations are: (i) there are two bursts of generation activity each day, beginning approximately three hours after high tide and lasting 4-6 hours; (ii) for each cycle production levels rapidly increase with tidal range, the output characteristic therefore displaying a 14-day cycle; (iii) high-water times shift by about $1 \mathrm{hr}$ per day; (iv) in each 14day period, the generation will not be evenly distributed throughout the 24-hr of the day; (v) output levels will only show slight variation from one fortnightly period to the next; and (vi) annual production levels will show fluctuations of around $+/-5 \%$ and will follow a cycle of $182 / 3$ years.

\subsubsection{Flood Generation}

Here, power is provided as the basin fills. The basin empties through sluices as the tide falls. This method is not as efficient as ebb generation since it involves using the basin between existing low tide level and slightly above normal mid-tide level, thus producing less energy. An advantage of this mode is that it facilitates the production of energy out of phase with a neighboring ebb generation scheme, complementing its output and perhaps providing some firm capacity. 


\subsubsection{Two-way Generation:}

This is a combination of ebb and flood generation, generating as the basin both fills and empties, but with a smaller power output for simple ebb generation (except at the highest tide ranges) due to reduced range within the basin. There is a resultant reduction in efficiency with two-way generation since turbines and water flow cannot be optimized. Two-way generation produces electricity in approximately 6-hr cycles, with smaller power output and a greater plant utilization factor.

\subsubsection{Tidal Stream}

Tidal current turbines are basically underwater windmills where tidal currents are used to rotate an underwater turbine. First proposed during the 1970s' oil crisis, the technology has only recently become a reality. Horizontal axis turbines are more commonly employed. Marine Current Turbines (MCT) \{http//www.marineturbines.com/home.htm $\}$ installed the first full-scale prototype turbine $(300 \mathrm{~kW})$ off Lynmouth in Devon, UK in 2003 . Their second project, a $1 \mathrm{MW}$ prototype, is expected soon. It will be followed by an array of similar systems (farm) to be installed in an open sea, where three turbines will be added to provide a total capacity of $5 \mathrm{MW}$. A similar project is the Hydro Helix project in France.

The Norwegian company Hammerfest Stom installed their first grid-connected $300 \mathrm{~kW}$ devise that was tested and the concept proven $\{\mathrm{http} / /$ www.e-tidevannsenergi.com/\} A tidal stream turbine has been designed for the Pentland Firth between the North of Scotland and the Orkney Islands [37] where the first design was for twin turbines with $20 \mathrm{~m}$ rotors and was rated at 1-2 MW depending on current speed. In today's design, the $60 \mathrm{~m}$ deep four $20 \mathrm{~m}$ rotors cover water flow rather than a pair to keep blade loads within practical limits and the whole power output is $4 \mathrm{MW}$. The SMD Hydrovision Tidal Project (UK) \{http//www.smdhydrovision.com\} consists of a pair of contra-rotating $500 \mathrm{~kW}$ turbines mounted together on a single crossbeam. The $1 \mathrm{MW}$ units are designed to be mounted in an offshore tidal environment with a peak tidal velocity of 5 knots $(2.5 \mathrm{~m} / \mathrm{s})$ or more and a water depth of greater than $30 \mathrm{~m}$. The Lunar Energy Project (UK) and the HyroHelix Energies Project (France) \{http//www.lunarenergy.co.uk http//www.hyrdohelix.fr/\} feature a ducted turbine fixed to the seabed via gravity foundation. A $1 / 20^{\text {th }}$ model was tested in 2004 and a 1 MW prototype is expected soon. The ideal sites are generally within several kilometers of the shore in water depths of 20-30 m.

There are also vertical axis turbines that are cross flow machines whose axis of rotation meets the flow of the working fluid at right angles. Cross flow turbines allow the use of a vertically oriented rotor that can transmit the torque directly to the water surface without need of complex transmission systems or an underwater nacelle. The vertical axis design permits the harnessing of tidal flow from any direction, facilitating the extraction of energy not only in two directions, the incoming and outgoing tide, but making use of the full tidal eclipse of the flow [38]. In these types of turbines, the rotational speed is very low, of the order of $15 \mathrm{rpm}$.

\subsubsection{The Enermax Project (Italy) \{http//www.pontediarchimede.com\}:}

This uses the Kobold turbine. Its main characteristic is its high starting torque that permits it to start even in loaded conditions. A pilot plant is located in the Straight of Messina, close to the Sicilian shore in Italy, in an average sea tidal current of $2 \mathrm{~m} / \mathrm{sec}$. 


\subsubsection{The Blue Energy Project (Canada) \{http//www.bluenergy.com\}}

Four fixed hydrofoil blades of the Blue Energy tidal turbine are connected to a rotor that drives an integrated gearbox and electrical generator assembly. The turbine is mounted in a durable concrete marine caisson that anchors the unit to the ocean floor, directs flow through the turbine further concentrating the resource supporting the coupler, gearbox, and generator above it. The hydrofoil blades employ a hydrodynamic lift principle that causes the turbine foils to move proportionately faster than the speed of the surrounding water. The rotation of the turbine is unidirectional on both the ebb and flow of the tide. A unit turbine is of the order of $200 \mathrm{~kW}$ output power. For large-scale power production, multiple turbines are linked in series to create a tidal fence across an ocean passage or inlet.

\subsubsection{The Gorlov Helical Turbine (GHT) (USA.\{http//www.gcktechnology.com/GCK/\}}

The turbine consists of one or more long helical blades that run along a cylindrical surface similar to a screw thread, having a airfoil or airplane wing profile. GHT blades provide a reaction thrust that can rotate the turbine faster than the water flow itself. The GHT is selfstarting and can produce power from water current flow as low as $1.5 \mathrm{~m} / \mathrm{sec}$ with power increasing in proportion to the water velocity cubed. Due to axial symmetry, the GHT always rotates in the same direction, even when tidal currents are reversed. The standard model ( $1 \mathrm{~m}$ in diameter, $2.5 \mathrm{~m}$ in length) can be installed either vertically or horizontally to the water current [39]. A single GHT has a rated power of $1.5 \mathrm{~kW}$ for $1.5 \mathrm{~m} / \mathrm{s}$ water speed and $180 \mathrm{~kW}$ for $7.72 \mathrm{~m} / \mathrm{sec}$. A similar concept to the GHT is the Achard known as the Harvest project (France) \{http//www.legi.hmg.inpg.fr/cavit/Deta/Harvest.html\}.

\subsubsection{Adaptation to Grid Network Requirements}

The output from a tidal plant displays characteristics that are not compatible with those of conventional generation, transmission, and system load. A pumping system increases average output levels and enhances flexibility of the scheme. This in turn leads to improved economic efficiency as supply times can be varied to match energy cost levels.

Single-action outflow (ebb) generation barrages can use one basin or a combination of basins, and can operate by ebb, flood, or two-way generation, with or without pumping.

\subsection{Proposed Severn Barrage}

Few sites worldwide are as close to electricity users and the transmission grid as are the potential sites in the UK.

The Severn is probably the most well known of all potential tidal energy locations, and projects for damming the Severn estuary date back for over a century. The tide range is up to $11 \mathrm{~m}$ near the head, being amplified and funneled by the Bristol Channel. The channel and estuary form a resonator having an effective length equivalent to $1 / 4$ of that of the tidal wave. Most attention is focused on schemes further down the estuary where tide range is reduced and a longer barrage is needed, but where the energy extractable is many times greater. Tidal resonance in the Severn Estuary is illustrated in Figure 4.12. 


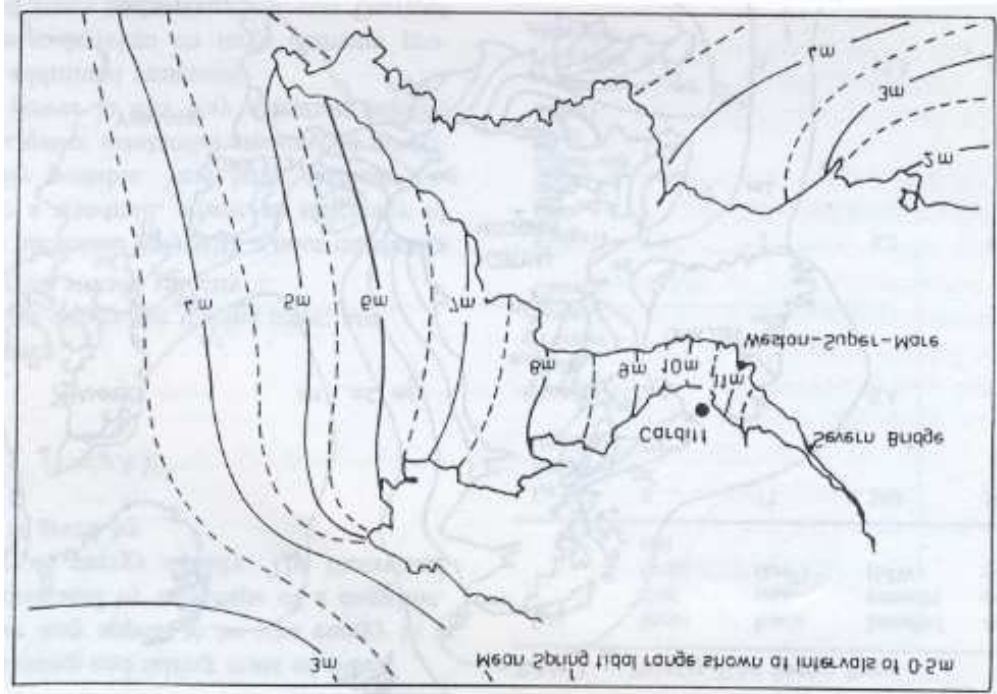

Fig. 4.13. Tidal resonance in the Severn Estuary.

A number of different barrage options have been proposed. The Cardiff-Weston scheme is one of the largest and would have a generating capacity of around 8.64GW. The Shoots scheme (which would run near to the two Severn road crossings) is $1.05 \mathrm{GW}$ with an annual output of around 2.75 TWh. Power output and cost summary for the two options are given in Table 4.7.

\subsubsection{Potential Benefits}

The assumption is that both barrages would be operated on the ebb tide, with the addition of flood pumping to increase total energy output. This means that they would be generating electricity for around 7 8 hours on each tide, and output would vary within this period. The annual output of each barrage is less than that implied by their size, around $4.4 \%$ of UK electricity supply, about the same as would be produced by a 2 GW conventional fossil-fuel or nuclear power station.

The high capital cost of a barrage project leads to a very high sensitivity to the discount rate used (Table 4.7). At a discount rat of $2 \%$ that could be justified for a climate change mitigation project, cost of electricity from both barrage proposals is highly competitive with other forms of generation. At a commercial discount rate of $>8 \%$, these costs escalate significantly, making private investment unlikely without significant Government market intervention. 


\begin{tabular}{|c|c|c|c|}
\hline & $\begin{array}{l}\text { Cardiff- } \\
\text { Weston }\end{array}$ & Shoots \\
\hline \multicolumn{2}{|c|}{ Length of Embankments } & $16.1 \mathrm{~km}$ & $4.1 \mathrm{~km}$ \\
\hline \multicolumn{2}{|c|}{ Generating Capacity } & $8.64 \mathrm{GW}$ & $1.05 \mathrm{GW}$ \\
\hline \multicolumn{2}{|c|}{$\begin{array}{l}\text { Annual Average Electricity } \\
\text { Output }\end{array}$} & $17 \mathrm{TWh}$ & $2.75 \mathrm{TWh}$ \\
\hline \multicolumn{2}{|c|}{$\begin{array}{l}\text { Contribution to UK Electricity } \\
\text { Supply (2006 Data) }\end{array}$} & $4.4 \%$ & $0.7 \%$ \\
\hline \multicolumn{2}{|l|}{$\begin{array}{l}\text { Estimated Cost of } \\
\text { Construction }\end{array}$} & $£ 15$ bn & $1.5 \mathrm{bn}$ \\
\hline \multirow{5}{*}{$\begin{array}{l}\text { Estimated cost of } \\
\text { output at various } \\
\text { discount rates } \\
\text { (high case } \\
\text { scenario) }\end{array}$} & $2 \%$ & $2.31 \mathrm{p} / \mathrm{kWh}$ & $2.58 \mathrm{p} / \mathrm{kWh}$ \\
\hline & $3.5 \%$ & $\begin{array}{l}3.68 \\
\mathrm{p} / \mathrm{kWh}\end{array}$ & $3.62 \mathrm{p} / \mathrm{kWh}$ \\
\hline & $8 \%$ & $\begin{array}{l}9.24 \\
\mathrm{p} / \mathrm{kWh}\end{array}$ & $7.52 \mathrm{p} / \mathrm{kWh}$ \\
\hline & $10 \%$ & $\begin{array}{l}12.37 \\
\mathrm{p} / \mathrm{kWh}\end{array}$ & $9.54 \mathrm{p} / \mathrm{kWh}$ \\
\hline & $15 \%$ & $\begin{array}{l}22.31 \\
\mathrm{p} / \mathrm{kWh}\end{array}$ & $15.38 \mathrm{p} / \mathrm{kWh}$ \\
\hline
\end{tabular}

Table 4.7. Power Output and Cost Summary for the Two Main Severn Barrage Options

There would be substantial flood risk benefits. The timing of output is not optimal, but output is not a major problem for the electricity grid that can be managed at very low cost. The output would displace output from fossil-fuelled plants and would make a genuine and sizable contribution to meeting the UK's targets on renewable energy and on reducing carbon dioxide emissions.

\subsubsection{Conditions for Sustainable Development}

The issue has been approached from a general position that favors renewable energy under which its development might be sustainable. It has been done within a framework that places a high value on long-term public interest and on maintaining the overall integrity of internationally recognized habitats and species.

\subsubsection{Energy Policy Contexts and Compliance with Environment Legislation}

There is risk that development of a barrage might divert Government's attention away from other necessary solutions to the challenge of climate change, including development of a more decentralized energy system and the reduction of energy demand. A Severn barrage has a number of disadvantages that are similar to those of nuclear power, and developing such a large amount of electricity generating capacity in a single location would not itself move the UK any closer to a more decentralized energy system. The Government does not have policies in place at this time to deliver the carbon savings that will be required by 2050, and in particular the delivery of emissions reductions over the next 15 years. A Severn barrage could be pursued as part of a major drive to reduce emissions substantially over both the short- and long-term. 


\subsubsection{UK Tidal Resource}

Available estimates of the UK's tidal range and tidal stream resource for potential electricity generation are given in Table 4.8. Estimating potential electricity output requires a number of assumptions on technical constraints of the devises installed, their efficiency, and effect of resource extraction on the remaining resource. This implies that there is a large degree of uncertainty in all resource estimates given in Table 4.8 .

\begin{tabular}{|l|c|l|l|c|}
\hline \multicolumn{2}{|c|}{ Tidal Range Sites } & \multicolumn{3}{c|}{ Tidal Stream Sites } \\
\hline $\begin{array}{c}\text { Site } \\
\text { Name }\end{array}$ & $\begin{array}{c}\text { Resource } \\
(\text { TWh/year })\end{array}$ & \multicolumn{1}{|c|}{ Site name } & $\begin{array}{c}\text { Aesource } \\
\text { (TWh/year })\end{array}$ \\
\hline Severn & 17 & Pentland Skerries & Pentland Firth & 3.9 \\
\hline Mersey & 1.4 & Stroma & Pentland Firth & 2.8 \\
\hline Duddon & 0.212 & Duncans-by Head & Pentland Firth & 2.0 \\
\hline Wyre & 0.131 & Casquets & Alderney & 1.7 \\
\hline Conwy & 0.06 & South Ronaldsay & Pentland Firth & 1.5 \\
\hline & & Hoy & Pentland Firth & 1.4 \\
\hline & & Race of Alderney & Alderney & 1.4 \\
\hline & & South Ronaldsay & Pentland Firth & 1.1 \\
\hline & & Rathlin island & North Channel & 0.9 \\
\hline & & Mull of Galloway & North Channel & 0.8 \\
\hline
\end{tabular}

Table 4.8. Top Tidal Energy Sites in the UK with the Resource

\subsection{Electricity Transmission System}

The Electricity Transmission Network in Great Britain is illustrated in Reference [40]. Most generating plants in Great Britain are connected to the transmission system, with some 12 GW of generating capacity connected to the distribution networks. The capacity of the transmission system to connect generation and manage the flows of electricity depends on the capacity of the network. The process of connecting to the network is based around the principle of matching the Connection Entry Capacity (CEC) (the generating capacity of the power station) with the Transmission Entry Capacity (TEC) (the capacity of the network to accept a new generator). Connection offers are made on the basis of an invest and connect approach whereby CEC can never exceed TEC, so new lines must be built to connect new generation. At present, there are significant TEC constraints in the north of England and in Scotland, which are preventing the connection of new generation projects. Areas of the transmission network will need to be upgraded to higher voltage levels to increase the TEC.

These issues pose significant challenges for the connection of tidal stream projects. Existing capacity constraints and delays to network upgrades will further delay the date by which tidal stream projects might be connected. If the current approach to transmission connection is not modified, it is unlikely that the UK will see any significant level of tidal stream connection before 2020 .

For tidal range, the situation is less significant. Firstly, tidal range resources are generally located in areas where grid constraints capacity transmission lines are less pronounced, and 
are closer to high capacity transmission lines and to centers of demand. Secondly, tidal barrages are likely to be larger one-off projects when compared to a tidal stream array, making the incorporation of grid connection costs a smaller part of the overall project cost and therefore more manageable.

The Severn Estuary area has significant network capacity for new generation, with negative transmission network use of system (TNUoS) charges currently in force. This applies for generators in the southwest of England due to a shortage of generation to meet local requirements.

The transmission network around the Severn Estuary is shown in Figure 4.14. It is quite well developed, with possible connections at both $400 \mathrm{kV}$ and $275 \mathrm{kV}$ on both sides of the estuary not far from the landing points for a barrage. For the larger Cardiff-Weston scheme, two connections into the $400 \mathrm{kV}$ network would be required at both north sides of the barrage (i.e. four connections in total) as the $275 \mathrm{kV}$ network on the north side is near to capacity and there is very limited capacity on the $132 \mathrm{kV}$ network on the south side.

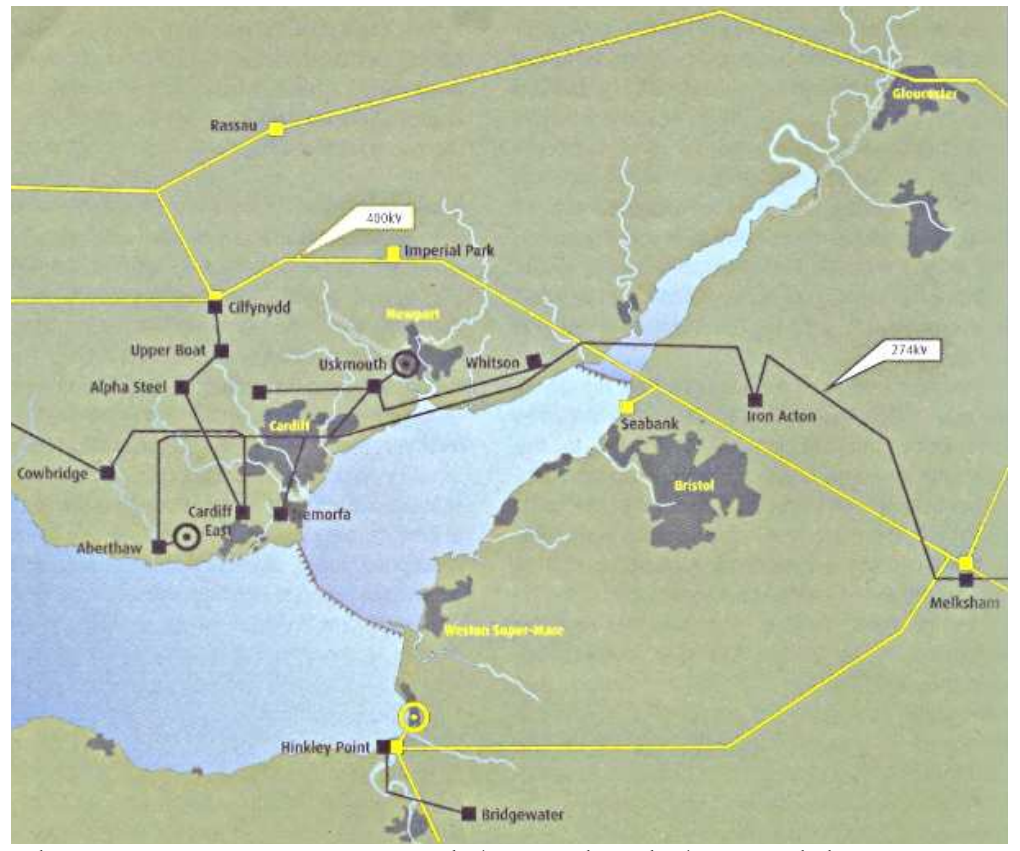

Fig. 4.14. Electricity transmission network (400 and 275kV) around the Severn Estuary.

For the much smaller-rated capacity of the Shoots scheme, all of the connection options seem to have sufficient capacity to accommodate this through just one connection. A connection to the Hinkley Point-Melksham 400kV double-circuit line would be appropriate due to high demand for new capacity. This could further increase with decommissioning of the nuclear power station at Hinkley Point (if it is not replaced by new nuclear generation). Both schemes would require some new transmission infrastructure to connect into the existing network. This requirement is far higher for the Cardiff-Weston scheme due to its higher rated capacity. 


\subsection{Feasibility Studies: Mersey Estuary, Loughor Estuary (Wales), Duddon Estuary (Cumbrian Coast), Wyre Barrage (Lancashire), and Thames Barrier}

\subsubsection{Mersey Barrage}

The first stage of the feasibility study was completed in 1988 [41], which included hydraulic and energy modeling together with a preliminary examination of the geo-technical conditions, socio-industrial benefits and likely effects on shipping and the ecology of the estuary. No overriding impediments to the construction of a barrage were identified at that time. The Mersey Estuary has a mean spring tidal range of $8 \mathrm{~m}$ and a potential annual resource of about 1.4 TWh. The barrage would have 28 turbine-generators with 8 -m turbines rated at $25 \mathrm{MW}$, giving an installed capacity of $700 \mathrm{MW}$ [42]. The proposed barrage would be approximately $2 \mathrm{~km}$ long, with a design life of at least 120 years for the main structure, with two periods of turbine renewal at 40-year intervals.

\begin{tabular}{|l|c|c|}
\hline \multicolumn{1}{|c|}{ Technology Option } & $\begin{array}{c}\text { Rated Capacity } \\
\text { (MW) }\end{array}$ & $\begin{array}{c}\text { Annual Electricity } \\
\text { Output (GWh }\end{array}$ \\
\hline Tidal lagoon (Zone 1) & 350 & 650 \\
\hline Tidal Barrage (Zone 2) & 700 & 1200 \\
\hline Central reservation (Zone 2) & 20 & 40 \\
\hline Constrained channel (Zone 2) & 50 & 100 \\
\hline Tidal fence (Zone 2) & 35 & 80 \\
\hline Tidal gate (Zone 3) & 380 & 700 \\
\hline Water wheel (Zone 3) & 200 & 500 \\
\hline
\end{tabular}

Source: Peel Environmental Ltd

Table 4.9. Comparison of Main Tidal Power Options for the Mersey Estuary.

There is renewed interest as a result of a recent study commissioned by Peel Environmental Ltd in association with the North West Regional Development Agency (NWDA) and the Mersey Basin Campaign [43]. There are a number of potential options for harnessing energy from the Mersey. To assess the options, the estuary was divided into study zones. These are indicated in Figure 4.15. The only viable option for zone 1 was considered to be a tidal lagoon. This could be operated independently from the other options. For the remaining zones, the two most productive options were two tidal barrage options (one termed as a tidal gate), although several tidal stream options were also studied.

The capacity and estimated electricity output from each option is indicated in Table 4.9. The construction cost of a Mersey Barrage is estimated at $£ 1.5 \mathrm{bn}$ (2006 prices). This results in a unit cost of output ranging from $12.27 \mathrm{p} / \mathrm{kWh}$ to $15.79 \mathrm{p} / \mathrm{kWh}$ when a commercial discount rate of $8-10 \%$ is assumed. This would reduce to about one third if a $2 \%$ discount rate were used. The costs using the higher discount rates would result in electricity that is not commercially competitive under current conditions. 


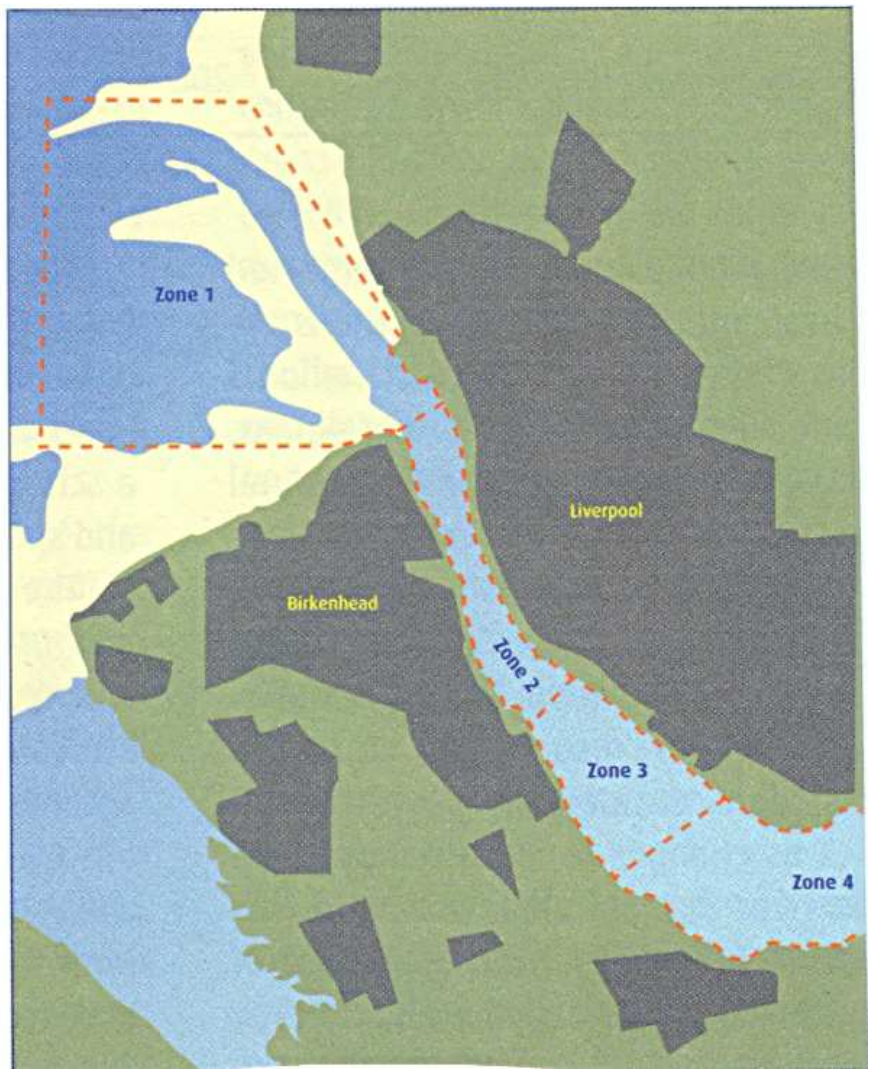

Source: Peel Environmental Ltd.

Fig. 4.15. Mersey showing study zones

\subsubsection{Other UK Barrages}

These include the Loughou Estuary in Wales which has an annual spring tide of $3.9 \mathrm{~m}$ and could generate $5 \mathrm{MW}$, the Duddon Estuary located on the Cumbrian coast that has a mean tidal range of $5.8 \mathrm{~m}$ and could generate $0.212 \mathrm{TWh} /$ year from ten $10 \mathrm{MW}$ turbines, the Wyre Barrage (Lancashire) with a mean tidal range of $6.6 \mathrm{~m}$ and installed capacity of around 60 MW that would generate about $0.131 \mathrm{TWh}$ /year, the Thames Barrier that would form a new flood protection barrier that could generate possibly up to $800 \mathrm{MW}$, and the Conwy Barrage (North Wales) that would have six 5.5-MW generators giving an installed capacity of 33 MW. Here, the mean tidal range varies from $7.1 \mathrm{~m}$ (spring) to $3.5 \mathrm{~m}$ (neap) and average energy is $0.0568 \mathrm{TWh}$ /year $(0.0602 \mathrm{TWh} /$ year with pumping)

\subsection{Environment Impact}

The Severn Estuary is a unique and dynamic environment. It has the second largest tidal range in the world, combined with a high-suspended sediment load, and has a number of special features, including extensive areas of salt marsh, and mobile sandbanks. It is an 
important site for migratory birds, and for fish movements in and out of the estuary's tributaries, such as the Wye and Usk. For these reasons the Severn Estuary has been designated a protected site under national and international legislation.

The most important pieces of conservation legislation for a prospective Severn barrage are the EU Directives on Birds and Habitats that protect sites designated as Special Protection Areas (SPAs) and Special Areas of Conservation (SACs). Identification of sites is a scienceled process that is based on protecting important ecosystem types and threatened bird species. The Severn Estuary is a SPA and a candidate SAC. The aim of designation is to protect against biodiversity loss by conserving a series of important or at-risk habitats and species that make up the Europe-wide Natura 2000 network. The Natura 2000 network is based on the need to conserve biodiversity across Europe, and internationally.

A Severn barrage could lead to a loss of biodiversity, resulting in the need for a compensatory habitats package to maintain overall integrity of the Natura 2000 network. The EU Directives provide a clear and robust legal framework for achieving sustainable development and therefore compliance with the Directive is a central condition for a sustainable Severn barrage. Providing compensatory habitat would be a very significant undertaking on a scale hitherto unprecedented in the UK. It would have to be an integral part of any barrage proposal.

In summary, there is a strong case to be made for a sustainable Severn barrage. Much wider and stronger action on climate change is a pre-requisite for UK Sustainable Development Commission's (SDC) support. There may be an environmental opportunity available by linking a compensatory habitats package to climate change adaptation. A Severn barrage must be publicly led as a project and publicly owned as an asset to ensure long-term sustainability. The Government should consider a range of innovative financing mechanisms that would maintain overall public control and ownership of the project.

\subsection{Carbon Emissions}

One of the main arguments for building a Severn barrage is its potential contribution to reducing carbon dioxide emissions and therefore its ability to help the UK meet its national and international obligations on renewables and emissions of greenhouse gases ${ }^{4}$

The reduction in carbon dioxide emissions from a Severn barrage depends heavily on assumptions made on the carbon intensity of the displaced electricity. The output from a tidal barrage is intermittent, is highly predictable, and has very low operational cost. It would be treated as base-load generation, similar to that for nuclear power plants. Therefore, tidal power output is most likely to displace the output from large, centralized, fossil fuel plants.

\footnotetext{
${ }^{4}$ Under the recently-agreed EU target for $20 \%$ of all energy requirements to come from renewables by 2020 www.defra.gov.uk/news/latest/2007/climate-0309.htm , the UK will need to commit to developing at least this amount. On greenhouse gases, it is assumed that the UK will need to make substantial progress in its goal for a $60 \%$ reduction in carbon dioxide emissions by 2050, and that the UK 's commitment will most likely need to rise to a $80-90 \%$ cut in line with scientific evidence.
} 
The long lifecycle of a Severn barrage has a positive impact on the carbon emissions factor as the embedded emissions from construction are counter-balanced by 120 years of zero emissions electricity generation. The emissions factor for the Severn Cardiff-Weston barrage is estimated to be $2.42 \mathrm{gCO}_{2} / \mathrm{kWh}$ and $1.58 \mathrm{gCO}_{2} / \mathrm{kWh}$ for the Shoots scheme, which translates into a carbon payback of around 5-8 months for the two schemes. It is in the very lowest category for power generation and compares well against other low carbon technologies such as nuclear power $\left(16 \mathrm{gCO}_{2} / \mathrm{kWh}\right)[44]$.

The Severn barrage would displace the need for some other form of new capacity, such as CCGT, as this is currently the preferred choice for new-build base-load generation. Newbuild gas-fired plant has a carbon intensity of around 90tC/GWh.

Table 4.10 presents the likely annual carbon savings (as both carbon and carbon dioxide) from the two Severn barrage proposals. Although it is possible to calculate the lifetime carbon savings (over the 120 years expected life of a barrage), the figures are unlikely to be realistic because over this period the generating capacity being displaced will be progressively less carbon intensive.

\begin{tabular}{|l|c|c|c|c|}
\hline \multirow{2}{*}{} & \multicolumn{2}{|c|}{$\begin{array}{l}\text { Cardiff- } \\
\text { Weston }\end{array}$} & \multicolumn{2}{c|}{ Shoots } \\
\cline { 2 - 5 } & $\mathrm{MtC}$ & $\mathrm{MtC}_{2}$ & $\mathrm{MtC}$ & $\mathrm{MtC}_{2}$ \\
\hline $\begin{array}{l}\text { Annual carbon savings } \\
\text { (based on 90tC/GWh) }\end{array}$ & 1.53 & 5.60 & 0.25 & 0.91 \\
\hline $\begin{array}{l}\text { Percentage reduction in UK } \\
\text { carbon emissions } \\
\text { (1990 baseline) }\end{array}$ & \multicolumn{2}{|c|}{$0.92 \%$} & \multicolumn{2}{c|}{$0.15 \%$} \\
\hline For Comparison & \multicolumn{4}{|l}{} \\
\hline $\begin{array}{l}\text { Annual carbon savings based on } \\
\text { average gas displacement } \\
\text { (100tC/GWh) }\end{array}$ & 1.7 & 6.22 & 2.75 & 1.00 \\
\hline $\begin{array}{l}\text { Annual carbon savings based on } \\
\text { grid mix displacement } \\
\text { (131tC.GWh) }\end{array}$ & 2.23 & 8.15 & 0.36 & 1.32 \\
\hline
\end{tabular}

Table 4.10. Potential Carbon Savings from a Severn Barrage.

\subsection{Physical Implications of a Barrage}

The construction, presence and operation of a Severn Barrage would involve major physical changes to water levels, geomorphology, and sedimentary processes. These physical changes underlie and have significant implications for (i) the environment-the estuarine ecosystem, inter-tidal and wetland habitats, birds, fish; and (ii) the economy and society at a local and regional scale - ports and navigation, land drainage and flooding, water quality, infrastructure and transport, employment, industry and recreation.

The changes that a barrage would cause extend well beyond the direct physical footprint of the structure, and involve physical changes to the estuary as a result of reducing the tidal 
range and changing the water levels within the barrage basin (upstream) and outside the barrage (downstream). The physical barrier across the estuary (Cardiff-Weston barrage is about $16 \mathrm{~km}$ long), together with the changes to water levels, the tidal currents and the wave regime of the estuary, also mean that the sedimentary and morphological characteristics and processes of the estuary would be significantly changed.

The hyper-tidal nature of the estuary is responsible for creating a series of unique conditions and habitats such as extensive mud flats and mobile sand banks and extracting energy from this dynamic regime in the form of a tidal barrage would fundamentally change the nature of the Severn Estuary. On the whole, a barrage would raise the average water level inside the basin by raising the low tide levels to around present mean sea level and by reducing high tide levels by up to $1 \mathrm{~m}$ (up to about $0.5 \mathrm{~m}$ for the Shoots scheme). The mean sea level in the estuary would be raised by some $2.5 \mathrm{~m}$ to $3 \mathrm{~m}$ for the Cardiff-Weston scheme. The overall effect is to reduce the tidal range by about $50 \%$. For the Cardiff-Weston scheme, the range would decline from $11.5 \mathrm{~m}$ to $4.5 \mathrm{~m}$ on spring tides, and $5.5 \mathrm{~m}$ to $2.5 \mathrm{~m}$ on neaps. For the Shoots scheme, the result would be a similar reduction in tidal range, from $12.5 \mathrm{~m}$ to $4.5 \mathrm{~m}$ on spring tides, and $6.5 \mathrm{~m}$ to $3.5 \mathrm{~m}$ on neaps. Down stream of a barrage, model predictions for the Cardiff-Weston alignment are that low water level would be raised somewhat and high water levels would be reduced, the effects declining with distance up to $75 \mathrm{~km}$ seawards.

Morphology refers to the form and development of the landscape. Morphology and the sediment regime have implications for the environment, the engineering of a barrage, and in relation to ports and navigation.

\subsection{Consensus View on Tidal Power in the UK}

\subsubsection{Tidal Power}

The UK has considerable tidal power resource that could be exploited to produce renewable electricity. Current estimates suggest that the UK total resource is divided roughly equally between tidal range and tidal stream potential, with a combined output equal to around $10 \%$ of UK electricity supply. All options for exploiting this resource should be considered as a narrow focus on just one project (a Severn barrage) could be detrimental to the development of a whole class of emerging tidal stream technologies, some of which could be sizeable generators of renewable electricity. There is no conflict between the tidal range and tidal stream technologies that could be deployed in the Severn. Tidal stream devises are unlikely to be viable in the Severn Estuary, but there are more appropriate conditions further out in the Bristol Channel where this might be viable. Small-scale tidal lagoon development could take place alongside a tidal barrage. Large-scale tidal lagoon development in the Severn Estuary would not offer any economic or environmental advantage over a barrage.

\subsubsection{Tidal Stream}

The long-term potential of tidal stream technologies, subject to constraints that might be imposed due to location-specific impacts upon the environment, natural marine processes, and long-term costs being acceptable, should be exploited [45]. The UK is in a unique position with superior tidal stream resource combined with devices being developed or 
tested. Tidal stream technologies could make a substantial contribution to the sustainable energies of the UK. Considering the progress that has been made on tidal stream, the objective now should be to stay the course. In many ways, the tidal stream industry is the same as wind power was 20 years ago, and the timescale for bringing prototype technologies to large-scale deployment needs to be as fast-tracked as possible.

\subsubsection{Policy Improvements}

There are a number of areas where Government policy could be improved. The support and funding structures need to be reviewed and improved in line with circumstances as they develop and change. A flexible approach could be taken on the future of the Department for Business, Enterprise and Regulatory Reform's (BERR) Marine Renewables Deployment Fund (MRDF), which has so far not had any applicants due to delays in getting demonstration projects off the ground. Lessons could be learnt from the success of the Scottish Government's $£ 8 \mathrm{~m}$ support package for marine energy technologies, which has had strong interest from both tidal and wave developers. Increased support for marine renewables under a branded Renewables Obligation is also very welcome. This may provide an opportunity to revise the support available under the MRDF so that it focuses on providing grant funding for project development and testing, with the aim of stimulating progress towards initial tidal arrays and pre-commercial schemes.

The European Marine Energy Center in the Orkney Island is an excellent example of public sector funding being used to stimulate public sector investment and innovation in a strategic and efficient manner. Looking to the future, it is thought that there is potential to exploit the activity entered around the European Marine Energy Center (EMEC) to develop a regional hub around the Orkney Island and parts of the Caithness coastline, away from the Pentland Firth for commercial testing of devices beyond the prototype stage. In the longterm, lack of transmission capacity would appear to be a serious constraint on development of the UK's tidal stream resource in the north of Scotland. This also impacts on the offshore and onshore wind industry and on wave power devises. There are a number of problems with the current regime for connecting renewable generation and a real absence of longterm thinking on solutions to overcome them. This has serious consequences for the UK's ability to meet its targets for renewable electricity and the more ambitious EU targets that will eventually be implemented.

\subsubsection{Strategic Planning and Consenting}

Lack of good baseline information on the marine environment and on effects of large-scale deployment of different devices is a real issue. The gaps have to be filled over time through research of a strategic and generic nature as well as by developers. The Scottish Government is in the process of completing a strategic environmental assessment for marine renewables around the west and north coasts of Scotland, and the Welsh Assembly Government is developing a marine renewable strategy. 


\subsubsection{Tidal Lagoons}

It is difficult to come to a clear view on the long-term potential of tidal lagoons due mainly to the lack of authoritative evidence and that the concept remains unproven. Government should investigate options to encourage one or more tidal lagoon demonstration projects.

\subsubsection{Tidal Barrages}

Extensive information is already available on the Severn Barrage that contains the majority of the UK's tidal range resource, and also for the Mersey. There does not seem to be an extensive overlap between tidal barrages and tidal stream devices, leading to the conclusion that they can, on the whole, be considered separately. The UK's potential for developing different tidal barrage options other than the Severn is extensive, but the reason why this potential has not been developed in the past is that they have not appeared to be economically viable. Further investigation into UK tidal barrage options outside the Severn Estuary should be considered on a case-by-case basis, as potential benefits will differ considerably.

\subsection{Acknowledgement}

This Chapter has been prepared and coordinated by T. J. Hammons, Chair of International Practices for Energy Development and Power Generation IEEE; UK Sustainable and Renewable Energy Group; University of Glasgow, UK. The UK Sustainable Development Commission is thanked for information that has been cited in this Chapter. Contributors include: Peter Meisen (President GENI, San Diego, CA, USA), Peter O'Donnell (Senior Energy Specialist, Manager Generation Solar and Renewables Programs, San Francisco Environment Organization, CA, USA); Omar Siddiqui (Senior Associate, Global Energy Partners LLC, Lafayette, CA, USA); Roger Bedard (Offshore Wave Energy Project Manager, EPRI, CA, USA), Andrew Mill (Managing Director European Marine Energy Center, UK); Mirko Previsic (Consultant-Offshore Renewables, Sacramento, CA, USA); Anthony T Jones (Senior Oceanographer, oceanUS consulting, Palm Springs, CA, USA); and Adam Westwood (Renewable Energy Manager, Douglas Westwood Ltd, Canterbury, UK). The Chapter is primarily based on an up-date of the invited panel session summary papers presented at the Panel Session on Harnessing the Untapped Energy Potential of the Oceans: Tidal, Wave, Currents and OTEC at the IEEE-PES 2005 General Meeting (GM2005) and in the book on Renewable Energy edited by T. J. Hammons published by Intech in December 2009 [46] and in Reference [47].

\subsection{References}

[1] T. J. Hammons. "Tidal Power", Proceedings IEEE, vol. 81, (3), pp. 419-433, 1993.

[2] Barry V. Davis, "A Major Source of Energy from the World's Oceans," IECEC-97 Intersociety Energy Conversion Engineering Conference, 1997,

[3] N.H. Halvorson, “Evaluation of Nova Energy Ltd.'s Hydro Turbine for (Canadian) Ministry of Employment and Investment", N.H. Halvorson Consultants Ltd.

[4] "Renewable Energy: Power for a Sustainable Future; Technology Update: (2001) Tidal Current Power Update \& Wave Power Update", Oxford University Press.

[5] Peter Fraenkel, "Renewables; Is the Tide Turning for Marine Current Turbines?", Modern Power System, Marine Current Turbines Ltd, London, UK, June 30, 2001. 
[6] R. Bedard, "Final Summary Report: Offshore Wave Power Feasibility Demonstration Project", (E2I EPRI Global WP009 - US), 2005..

[7] Mirko Previsic, "System Level Design, Performance and Costs for San Francisco Pelamis Offshore Wave Power Plant", (E2I EPRI Global - 006A - SF), 2004.

[8] George Hagerman , "Offshore Wave Power in the US: Environmental Issues", (E2I Global EPRI - 007 - US), 2004.

[9] Bonnie Ram , “Wave Power in the US: Permitting and Jurisdictional Issues”, (E2I Global EPRI DOE NREL - 008 - US)

[10] M. Previsic, "Wave Power Technologies", Proceedings of the IEEE PES 05 GM, San Francisco, paper 05GM0542, June 2005, pp. 1-6.

[11] E2i/EPRI WP-004-US Rev 1 Assessment of Offshore Wave Energy Conversion Devices

[12] E2i/EPRI WP-005-US Methodology, Guidelines and Assumptions for the Conceptual Design of Offshore Wave Energy Power Plants (Farms)

[13] E2i/EPRI WP-006-HI System Level Design, Preliminary Performance and Cost Estimate - Hawaii -

[14] E2i EPRI WP-006-OR System Level Design, Preliminary Performance and Cost Estimate - Oregon

[15] E2i/EPRI WP-006-ME System Level Design, Preliminary Performance and Cost Estimate - Maine

[16] E2i/EPRI WP-006-MA System Level Design, Preliminary Performance and Cost Estimate - Massachusetts

[17] E2i/EPRI WP-006-SFa System Level Design, Preliminary Performance and Cost Estimate - San Francisco, California Pelamis Offshore Wave Power Plant

[18] E2i/EPRI WP-006-SFb System Level Design, Preliminary Performance and Cost Estimate - San Francisco Energetech Offshore Wave Power Plant

[19] Sea Technology Magazine August 2003, Wave Energy Conversion - The State of the Art

[20] EPRI - RE Technical Assessment Guide Ocean Wave Power Section for the years 2001, 2002 and 2003

[21] California Energy Commission - Wave Energy Resource Assessment for the State of California

[22] A.D. Trapp and M. Watchorn, "EB development of tidal stream energy," in Proceedings MAREC 2001, p. 169-173, 2001.

[23] A.T. Jones and A. Westwood, “Economic Forecast for Renewable Ocean Energy Technologies," presented at EnergyOcean 2004, Palm Beach, Florida, 2004.

[24] A.T. Jones and W. Rowley, "Global Perspective: Economic Forecast for Renewable Ocean Energy technologies," MTS Journal, vol. 36. No. 4, pp. 85-90, Winter 2002.

[25] N.J. Baker, M.A. Mueller, M. Watchorn, D. Slee, L. Haydock and N. Brown, “Direct drive power take off for the Stingray tidal current generator," in Proceedings MAREC 2002, p. 1-10, 2002.

[26] A. M. Gorlov, "The Helical Turbine and its Applications for Tidal and Wave Power," in Proc. OCEANS 2003, p. 1996, 2003.

[27] P.W. Ullman, "Offshore Tidal Power Generation - A new approach to power conversion of the oceans' tides," MTS Journal, vol. 36. no. 4, pp. 16-24, Winter 2002.

[28] P. Breeze, "The Future of Global Offshore Wind Power," Reuter Business Insight 2004.

[29] L. Coakley, "Long Island Offshore Wind Park - 140 Megawatts of Offshore Wind Energy," presented at EnergyOcean 2004, Palm Beach, Florida, 2004. 
[30] O. Siddiqui and R. Bedard, "Feasibility Assessment of Offshore Wave and Tidal Current Power Production", Proceedings of the IEEE PES 05 GM, San Francisco, paper 05GM0538, June 2005, pp. 1-7.

[31] E2i/EPRI WP-08-US- Identification of Permitting Issues

[32] A. T. Jones and A. Westwood, "Recent Progress in Offshore Renewable Energy Development", Proceedings of the IEEE PES 05 GM, San Francisco, paper 05GM0543, June 2005, pp. 1-6.

[33] A. C. Baker. Tidal Power. United Kingdom: Peter Peregrinus Ltd. 1991.

[34] A. C. Baker, The development of functions relating cost and performance of tidal power schemes and their application to small-scale sites. Tidal Power. London: Thomas Telford, 1986.

[35] M. Banai and A. Bichon. Tidal Power in France: The Ranch tidal power station: Some results after 15 years of operation, Energy Digest, pp. 39-45, October 1982.

[36] A. D.Grant. Power Generation from tidal flows for navigation buoys, $2^{\text {nd }}$ Int. Symp, Wave and Tidal Energy. BHRA, Cambridge, September 1981, pp. 117-128.

[37] I. G. Bryden et.al. Assessing the Potential of a Simple Tidal Channel to Deliver Useful Energy, Applied Ocean Research, Vol. 26, 2003, pp. 198-204.

[38] S. Kiho, et. al. The Power Generation from Tidal Currents by Darrieus Turbine, Renewable Energy, Vol. 9, (1-4), 1996, pp. 1242-1245.

[39] A. M. Gorlov. The Helical Turbine and its Application for Tidal and Wave Power. Proceedings IEEE OCEANCS'03, Vol. 4, San Diego (USA), September 2003, pp. 1996.

[40] NGET (2007). GB 7 year Statement. www.nationalgrid.com/uk/electricity/sys/current/

[41] Tidal Power from the River Mersey: A feasibility Study-Stage 1 Report. Mersey Barrage Co., 1988

[42] N. W. Hammond and P. Wood. Tidal Power from the Mersey: History and Prospects, in Developments in Tidal Energy, Proc. 3rd Conf. Tidal Power, London, UK, November 1989.

[43] Peel Environmental Ltd (2007). Mersey Tidal Power Study. www.merseytidalpower.co.uk

[44] Sustainable Development Commission (SDC). Paper 2, Reducing $\mathrm{CO}_{2}$ Emissions-Nuclear and the Alternatives. From the SDC Project 'The Role of Nuclear Power in a Low Carbon Economy' \{www.sd-commission.org.uk/pages/060306.html\}.

[45] T. J. Hammons. Energy Potential of the Oceans in Europe and North America: Tidal, Wave, Currents, OTEC, and Offshore Wind. International Journal of Power and Energy Systems, Paper 203-4142, Vol. 28, (4), 2008, pp. 416-428.

[46] T. J. Hammons. Book: Renewable Energy (T J Hammons (Ed.)), InTech, ISBN: 978-9537619-52-7, 580 p.,2009. Available on Line.

[47] T. J. Hammons. Tidal Power in the UK and Worldwide to Reduce Greenhouse Gas Emissions, International Journal of Engineering Business Management (IJEBM), Vol.3, (2), May 2011, 11 p. 


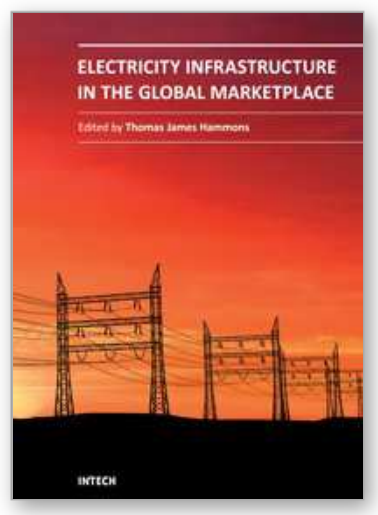

\author{
Electricity Infrastructures in the Global Marketplace \\ Edited by
}

ISBN 978-953-307-155-8

Hard cover, 802 pages

Publisher InTech

Published online 27, June, 2011

Published in print edition June, 2011

This book discusses trends in the energy industries of emerging economies in all continents. It provides the forum for dissemination and exchange of scientific and engineering information on the theoretical generic and applied areas of scientific and engineering knowledge relating to electrical power infrastructure in the global marketplace. It is a timely reference to modern deregulated energy infrastructure: challenges of restructuring electricity markets in emerging economies. The topics deal with nuclear and hydropower worldwide; biomass; energy potential of the oceans; geothermal energy; reliability; wind power; integrating renewable and dispersed electricity into the grid; electricity markets in Africa, Asia, China, Europe, India, Russia, and in South America. In addition the merits of GHG programs and markets on the electrical power industry, market mechanisms and supply adequacy in hydro-dominated countries in Latin America, energy issues under deregulated environments (including insurance issues) and the African Union and new partnerships for Africa's development is considered.

Thomas James Hammons (Fellow IEEE 1996) received the B.Sc. degree in Engineering (1st Class Honors), and the DIC, and Ph.D. degrees from Imperial College, London, UK He is a member of the teaching faculty of the School of Engineering, University of Glasgow, Scotland, UK. He was Professor of Electrical and Computer Engineering at McMaster University, Hamilton, Ontario, Canada in 1978-1979. He is the author/co-author of over 440 scientific articles and papers on electrical power engineering and is Editor of a book on Renewable Energy that was published by INTECH in December 2009. He has lectured extensively in North America, Africa, Asia, and both in Eastern and Western Europe.

Dr Hammons is Past Chair of the United Kingdom and Republic of Ireland (UKRI) Section IEEE and Past Chair of International Practices for Energy Development and Power Generation of IEEE. He is also a Past Chair of the IEEE PES Task Force on harmonizing power-engineering standards worldwide and Past Permanent Secretary of the International Universities Power Engineering Conference. He is a Chartered Engineer (CEng) and a registered European Engineer in the Federation of National Engineering Associations in Europe.

\title{
How to reference
}

In order to correctly reference this scholarly work, feel free to copy and paste the following:

T. J. Hammons (2011). Energy Potential of the Oceans in Europe and North America: Tidal, Wave, Currents, OTEC and Offshore Wind, Electricity Infrastructures in the Global Marketplace, (Ed.), ISBN: 978-953-307-1558, InTech, Available from: http://www.intechopen.com/books/electricity-infrastructures-in-the-globalmarketplace/energy-potential-of-the-oceans-in-europe-and-north-america-tidal-wave-currents-otec-andoffshore-win 
InTech Europe

University Campus STeP Ri Slavka Krautzeka 83/A 51000 Rijeka, Croatia Phone: +385 (51) 770447 Fax: +385 (51) 686166 www.intechopen.com

\section{InTech China}

Unit 405, Office Block, Hotel Equatorial Shanghai No.65, Yan An Road (West), Shanghai, 200040, China 中国上海市延安西路65号上海国际贵都大饭店办公楼405单元 Phone: +86-21-62489820

Fax: $+86-21-62489821$ 
(C) 2011 The Author(s). Licensee IntechOpen. This chapter is distributed under the terms of the Creative Commons Attribution-NonCommercialShareAlike-3.0 License, which permits use, distribution and reproduction for non-commercial purposes, provided the original is properly cited and derivative works building on this content are distributed under the same license. 